This article is a non-peer reviewed preprint published at EarthArXiv.

The article is in review by Geochimica et Cosmochimica Acta.

\section{Statistics and segmentation:}

\section{Using Big Data to assess Cascades Arc compositional variability}

\author{
Bradley W. Pitcher ${ }^{1}$ and Adam JR. Kent ${ }^{2}$ \\ ${ }^{1}$ Earth and Environmental Sciences department, Vanderbilt University, Nashville, TN 32701. \\ Email: bradley.w.pitcher@vanderbilt.edu \\ ${ }^{2}$ College of Earth, Ocean, and Atmospheric Sciences, Oregon State University, Corvallis, OR 97333. \\ Email: Adam.Kent@geo.oregonstate.edu
}


This article is a non-peer reviewed preprint published at EarthArXiv.

The article is in review by Geochimica et Cosmochimica Acta.

\section{Introduction}

The composition of magmas erupted at arc volcanoes bear evidence of the complex interplay between geochemical contributions from subducted oceanic crust, sediment, and liberated fluids, and from the mantle wedge and overlying lithosphere. The composition and mass contributed from each of these varies worldwide and even within a single arc (Hildreth and Moorbath, 1988; Elliott, 2003; Carr et al., 2004; Schmidt et al., 2008). This diversity is made even more complex by the fact that other parameters such as the rate and angle of subduction, slab age, mantle flow patterns, and thickness and tectonics of the overlying lithosphere may also greatly affect the composition of arc magmas (Patino et al., 2000; Syracuse and Abers, 2006; Till et al., 2013). Comparing along-arc compositional changes to variability in these parameters provides an excellent means by which to identify those that may be most responsible for production of heterogenous magmas within a single arc system. This, in turn, provides a more comprehensive understanding of the complex magmatic processes that occur within arcs worldwide.

Systematic intra-arc changes in volcanic rock compositions have been demonstrated for many systems around the world, and numerous causes have been proposed for each. For example, in the Central American Volcanic Arc (CAVA), systematic trends towards lower $\mathrm{La} / \mathrm{Yb}$ and higher $\mathrm{U} / \mathrm{Th}$ and $\mathrm{Ba} / \mathrm{La}$ in mafic lavas from the Nicaragua portion of the arc may indicate higher degree partial melting and greater contribution from the slab (Carr et al., 2004). This trend may be the result of a steeper slab angle in the central arc which could act to concentrated fluid-flux (Patino et al., 2000; Shaw et al., 2003). Wörner et al. (1994) explore geochemical variations in volcanoes from the Central Andes (17.5-22 $\mathrm{S})$ and suggest that crustal age is the predominant factor producing heterogeneity since crustal thickness, sediment supply, slab depth, and distance from trench are invariant over this portion of the arc. Along-arc changes in the Indonesian Sunda arc have been attributed to mantle heterogeneity and slab depth (Whitford et al., 1979) or differing sediment compositions and degree of melting (Turner and Foden, 2001). Thus, along-strike trends in geochemistry are a common feature in arcs worldwide and provide a window into the effects that each factor has on arc geochemistry.

Numerous authors have also demonstrated along-arc compositional variability of the Cascades volcanic arc (Leeman et al., 1990; Bacon et al., 1997; Schmidt et al., 2008; Mullen et al., 2017), as well as differences in the spacing between volcanoes, volumetric production, and 
This article is a non-peer reviewed preprint published at EarthArXiv.

The article is in review by Geochimica et Cosmochimica Acta.

71 eruptive style (Guffanti and Weaver, 1988; Sherrod and Smith, 1990; Hildreth, 2007). Schmidt et

72 al. (2008) suggest that the Cascades arc can be partitioned into four segments based on

73 abundance trace element and isotopic data, as well as relative abundance of several primitive

74 lava types (i.e. calc-alkaline, tholeiitic, intraplate, and absorokite). The four segments are: The

75 North (Mt. Meager to Glacier Peak), Columbia (Mt. Rainier to Mt. Jefferson), Central (Three

76 Sisters to Medicine Lake), and the South Segments (Mt. Shasta to Lassen Peak). These

77 boundaries were defined such that the geochemical composition of primitive lavas is visually

78 similar within a segment but are relatively distinct between segments. The definition of these

79 segments has been adopted by numerous subsequent authors working on Cascades volcanoes.

80 However, although this work made great strides in understanding the geochemical variability of

81 the arc, it is based on a relatively small data set $(\mathrm{n}=390)$ that is strongly spatially biased towards

82 just 14 of the over 3,400 Quaternary volcanic vents (Hildreth, 2007) of the Cascades arc (Fig. 1,

83 red columns) and did not use a statistically rigorous scheme to identify different segments.

To infer more robust conclusions about the causes of large-scale variability within an arc requires that there is adequate geochemical data to fully characterize the compositional range within each region and provide comprehensive spatial coverage of the entire arc. The Cascades is one of the most highly studied arcs in the world, and the tremendous volume of geochemical data that exists for this arc has not been utilized in its entirety by previous studies. This provides a unique opportunity to apply more advanced statistical methods that were developed for larger datasets to address Cascades arc variability in a novel way.

However, while a large dataset mitigates problems of incomplete sampling, this sampling is inherently uneven; certain volcanoes within an arc tend to be oversampled, while other less popular edifices remain poorly studied. This is a problem for studies that seek to address large scale questions such as variability over an entire arc, since the oversampled volcanoes overwhelm the overall trends, while compositions erupted at the rest of the volcanoes may not be adequately represented. For example, in the Cascades arc, two volcanoes, Mount Adams and Mount St. Helens, account for approximately $20 \%$ of all mafic data from Cascades arc literature. Thus, simple calculations involving a comprehensive arc-wide dataset are highly skewed towards the compositions of these two volcanoes and the local, rather than regional, processes that produce them. In this case statistical treatment of these data can help avoid the ill-effects of sampling bias and allow for more robust interpretations of larger, more representative datasets. 


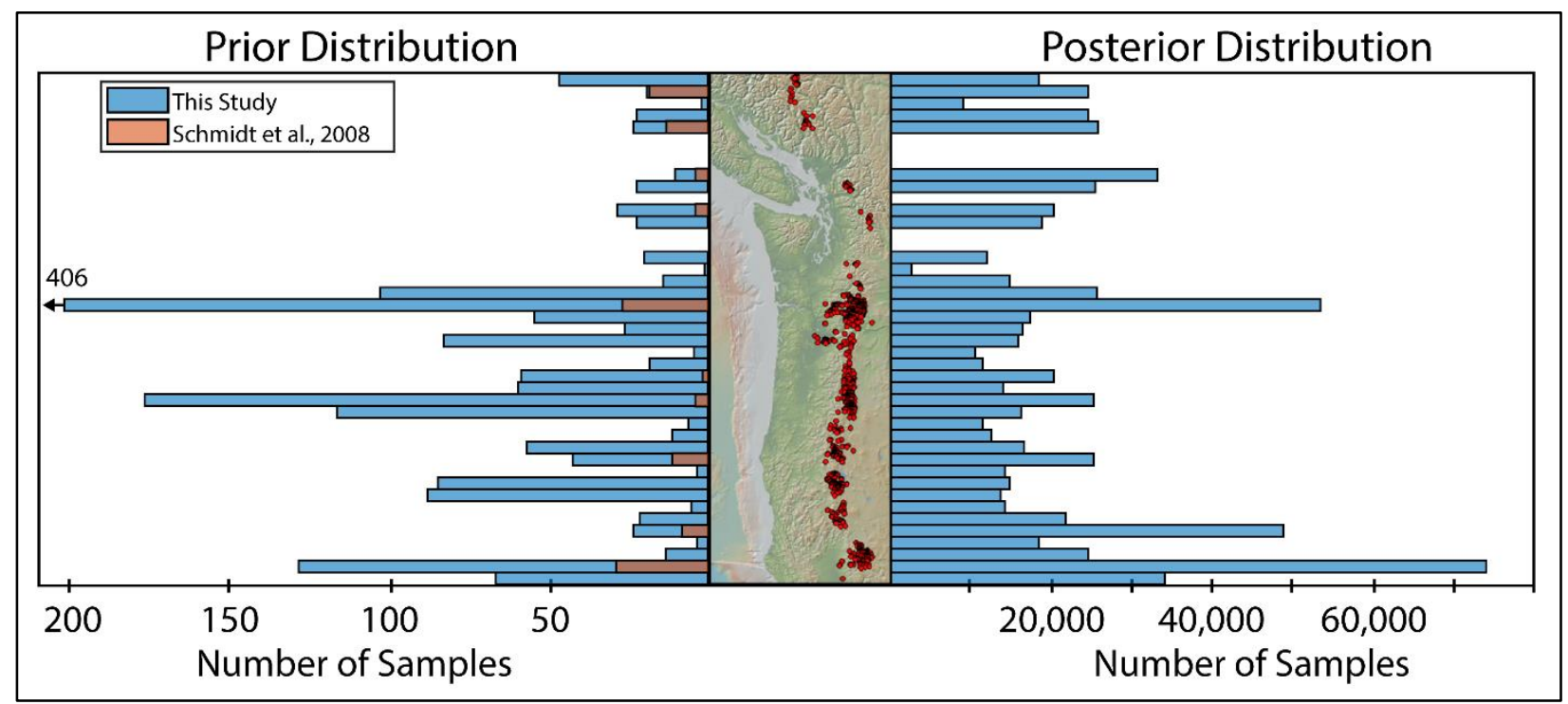

Figure 1: The histogram on the left shows the distribution of mafic samples used by Schmidt et al., 2008 (red) compared to the mafic arc-front dataset used in this study (blue). Bins are $0.25^{\circ}$ latitude. The map in the middle shows the locations of samples used in our study. Only arc-front samples are shown. The histogram on the right shows the posterior distribution after the Monte Carlo simulation with bootstrap resampling. Note that the posterior distribution is much more evenly distributed than the prior distribution, thereby reducing the inherent sampling bias of the comprehensive dataset.

For our study, we compile major and trace element and isotopic data on 13,000 samples from nearly 250 different publications and use multivariate statistical techniques to more thoroughly assess geochemical variability along the Cascades arc. Our study consists of two parts. We first re-examine the segments proposed by Schmidt et al. (2008) with this more representative dataset, utilizing a Monte Carlo bootstrapping approach to reduce sampling bias. We then use multivariate statistics to quantify differences among the segments, and to test whether they are statistically distinct from each other. In the second part of our study, we develop a multivariate clustering technique to objectively establish a more statistically robust segmentation scheme.

To our knowledge, this study is the first of its kind to use rigorous multivariate statistics

112 to address geochemical variability within a single arc. By compiling and utilizing a more

113 representative dataset, reducing the influence of oversampled volcanoes, and partitioning the arc

114 into regions that are most geochemically distinct from each other, we can better assess the 115 petrogenetic causes of geochemical variability along the Cascades arc.

Along-arc compositional variability in the erupted volcanic rocks of the Cascades arc may be the result of observed differences in subduction geometry or the composition of slab, 
This article is a non-peer reviewed preprint published at EarthArXiv.

The article is in review by Geochimica et Cosmochimica Acta.

119

120

121

122

123

124

125

126

127

128

129

130

131

132

133

134

135

136

137

138

139

140

141

142

143

144

145

146

147

148

149

mantle or overlying lithosphere that occur over the $1200 \mathrm{~km}$ arc (Guffanti and Weaver, 1988; Leeman et al., 1990; Hildreth, 2007; Mullen et al., 2017). These along-arc changes are briefly summarized below:

\subsection{Subduction geometry}

Subduction transitions from nearly orthogonal in the north to highly oblique in the south. The age of the slab that is subducted ranges from 3-5 Ma in the northernmost and southernmost regions of the arc, to $10 \mathrm{Ma}$ near the California-Oregon border (Wilson, 2002). The slab itself may also be highly segmented, with differing angles, and slab gaps and tears that may allow enriched sub-slab mantle into the overlying wedge (Porritt et al., 2011; Gao and Shen, 2014). Finally, the depth of the slab beneath the arc volcanoes range from $<70 \mathrm{~km}$ under Mt. St. Helens, to $>90 \mathrm{~km}$ for Glacier Peak, Lassen Peak, and rear-arc volcanoes (McCrory et al., 2012).

\subsection{Subducted slab composition}

The Gorda plate, which is subducted beneath the California portion of the arc, has a more depleted MORB composition than that of the Juan de Fuca plate (Davis et al., 2008; Gill et al., 2016). The Gorda plate and the northernmost portion of the Juan de Fuca plate are more intensely fractured, which may introduce more subduction fluid to the mantle wedge beneath the northern and southern portions of the arc than the central arc (Schmidt et al., 2008). Furthermore, sediment abundance and composition also vary significantly from north to south on both the Juan de Fuca and Gorda plates (Carpentier et al., 2014).

\subsection{Mantle Heterogeneity}

Some authors suggest that the mantle beneath the arc is heterogeneous and contains many isotopically distinct domains, which are sampled throughout the arc (Bacon et al., 1997). However, Mullen et al. (2017) hold that there are only three isotopically distinct mantle compositions which are sampled by the northernmost Garibaldi segment, the High Cascades, and the rear-arc Simcoe Volcanic Field. In addition, mantle flow patterns may be toroidal around slab edges, and the degree of melting may be highly dependent on position relative to slab edges or gaps (Long, 2016, and references therein). 
This article is a non-peer reviewed preprint published at EarthArXiv.

The article is in review by Geochimica et Cosmochimica Acta.

\subsection{Lithospheric heterogeneity}

Lithology changes from 50-km thick Paleozoic accreted terranes and old cratonic lithosphere in the north, to 50-55 Ma accreted oceanic plateau in the central part of the arc (Phillips et al., 2017), and the Paleozoic Klamath Terrain in the south (Schmidt et al., 2008). Regional tectonics also change along arc from compressional in the north to extensional in the south (Wells and McCaffrey, 2013; Brocher et al., 2017).

\section{Methods}

\subsection{Data compilation, filtering, and categorization}

To fully characterize the geochemical heterogeneity of the Quaternary Cascades arc, we carefully compiled a comprehensive dataset from the literature (Appendix 1). To do this, we used three online data repositories: EarthChem, GeoRoc, and the U.S. Geological Survey (USGS) National Geochemical database. Data from these databases were carefully concatenated such that no repeat analyses were included. We manually added data from 98 other sources, including many theses and dissertations, that were not found by the aforementioned databases. Only whole rock or glass analyses of Quaternary volcanic rocks were used. The study was limited to the Quaternary since significant changes have occurred in some portions of the arc since the initiation of the current High Cascades arc axis in the late Neogene (e.g. Pitcher et al., 2017). We compiled all analyses for a given sample into one line of data; for each element, priority was given to the most recent data from the most precise analytical method (e.g. decreasing priority methods for major elements are X-ray fluorescence, wet chemistry, electron microprobe, and then atomic emission and absorption spectrometry). We removed analyses that were collected before 1970 ( $\mathrm{n}=245$ samples) to increase the likelihood of retaining only higher quality data. We converted all iron data to $\mathrm{FeO}^{*}$, removed all samples with analytical totals $<90 \%$, as suggested by WoldeGabriel et al. (2005), and normalized all major element data to totals of $100 \%$.

Because the processes of magma generation and differentiation within the rear-arc may differ from those of the volcanic front (e.g. Pearce and Stern, 2006), we created a separate dataset for the rear-arc volcanic centers (i.e. Simcoe Volcanic field, Newberry Volcano, and Medicine Lake). USGS geological maps were used to constrain the longitudinal boundary for these three rear-arc provinces. In total, our dataset includes 4,035 samples from the rear-arc, which accounts $31 \%$ of all Cascades samples (Table 1). 
This article is a non-peer reviewed preprint published at EarthArXiv.

The article is in review by Geochimica et Cosmochimica Acta.

181

182

183

184

185

186

187

188

189

190

191

192

193

194

195

196

In addition, since compositional differences in felsic rocks may indicate the influence of very different processes than along-arc variability in mafic rocks, we separated the dataset into three compositional groups: mafic ( $\left.<52 \mathrm{wt} . \% \mathrm{SiO}_{2}\right)$, intermediate (52-62.99 wt.\%), and felsic ( $\geq 63$ wt.\%). For the samples that did not have $\mathrm{SiO}_{2}$ data, we used the rock names given by the author. In addition, a separate dataset was created for more primitive samples ( $\mathrm{MgO}>7 \mathrm{wt} . \%$, Mg\# > 57.5) (ca. Schmidt et al., 2008).

Although a major goal of this study is to fully characterize the compositional range of the Cascades, outliers greatly affect the results of multivariate statistical techniques such as those implemented in this study (Tryon et al., 2011). Thus, we utilized a two-stage Chauvenet's criterion for rejection to remove outliers. Unlike more traditional methods, such as removing values beyond $2 \sigma$ from the mean or 1.5 times the interquartile range from the median, the cutoff point for Chauvenet's criterion is also dependent on the number of analyses used. After the removal of outliers, our data compilation includes over 250,000 analyses on nearly 13,000 different samples. Of these, $35 \%$ are mafic samples, $48 \%$ are intermediate, and $17 \%$ are felsic (Table 1). However, this study is based only on the 4,610 mafic samples within the data compendium.

Table 1: Number of samples and analyses in our Cascades data compilation.

\begin{tabular}{r|cccc} 
& Arc-front & Rear-arc & All data & Analyses \\
\hline Primitive & 1,064 & 853 & 1,917 & 37,756 \\
Mafic & 2,037 & 2,573 & 4,610 & 88,309 \\
Intermediate & 5,178 & 1,020 & 6,198 & 122,523 \\
Felsic & 1,714 & 442 & 2,156 & 40,678 \\
\hline Total & 8,929 & 4,035 & 12,964 & 251,510
\end{tabular}

\subsection{Reducing Sampling bias: Weighted bootstrap resampling}

To better characterize along-arc variability, and to reduce sampling bias associated with well-studied locations we used a Monte Carlo method with a weighted bootstrap resampling. Bootstrap resampling, or bootstrapping, refers to any statistical technique that involves iterative random sampling from a population, with replacement after each sample is drawn. Repeating this sampling many times $(n>10,000)$, referred to as a Monte Carlo technique, increases the likelihood that the mean and standard deviation of the sample set accurately represent that of the entire population. This technique is especially powerful in reducing sampling bias when an 
This article is a non-peer reviewed preprint published at EarthArXiv.

The article is in review by Geochimica et Cosmochimica Acta.

205

206

207

208

209

210

211

212

213

214

215

216

217

218

219

220

221

222

223

224

225

226

227

228

229

230

231

232

233

234

inverse weighting scheme is used, such that each analysis from under-sampled regions are given a much higher probability of being selected during bootstrapping, compared to those from oversampled regions. Thus, analyses from under-sampled regions are "pulled up by their bootstraps" to create a new "posterior distribution" that is much more uniform than the original "prior distribution" (Fig. 1).

For our study, we first separated the data into bins of $0.25^{\circ}$ latitude ("latbins"). Then, we assigned each sample a weight, or probability of selection $(0.05 \leq \mathrm{W} \leq 1)$, that is inversely proportional to the number of analyses within its latbin. The weight given to each element within each latbin $\left(W_{i}\right)$ was calculated by dividing number of analyses of a given element within that latbin $\left(N_{i}\right)$ into that of the bin that contains the least samples for a given segment $\left(N_{\min }\right)$, $\left(W_{i}=\frac{N_{\min }}{N_{i}}\right)$. This was done separately for each compositional group (e.g. mafic and primitive). Since samples often did not contain the full suite of major and trace elements, the final weight given to all samples within a latbin ( $W_{\text {latbin }}$ ) was calculated by taking the median of the weights of all elements within that latbin: $W_{\text {latbin }}=\operatorname{median}\left(\frac{\min \left(N_{\left.S_{i O 2}\right)}\right.}{N_{S i O 2}}, \frac{\min \left(N_{T i O 2}\right)}{N_{T i O 2}}, \ldots, \frac{\min \left(N_{Y b}\right)}{N_{Y b}}\right)$. We used a minimum weight of 0.05 , such that the locations that are most highly sampled (i.e. Mt. St. Helens) are not completely disregarded (Keller and Schoene, 2012). Thus, the improvement in the posterior distribution was limited to 20 times (Fig. 1).

Bootstrap sampling was implemented via a MATLAB code. Our procedure was as follows:

1) For each bootstrap iteration, a random number, $r$, between 0 and 1 is assigned to each sample in the dataset. MATLAB uses a Mersenne Twister pseudorandom number generator, which has been shown to be sufficiently close to true randomness (Matsumoto and Nishimura, 1998). New $\mathrm{r}$ values are generated for each iteration

2) Each sample for which $W>r$, was "chosen" for that round.

3) For each element of the chosen sample, a random value is drawn from a Gaussian distribution formed by $\mu=$ reported value, $\sigma=$ analytical error, and all these values for a chosen sample are added to the bootstrap subset.

4) Step (3) is completed for each chosen sample ( $\mathrm{W}>\mathrm{r}$ ) of that bootstrap iteration.

5) The bootstrap subset from this iteration is concatenated to the subsets from all previous iterations into a single Monte Carlo results set 
This article is a non-peer reviewed preprint published at EarthArXiv.

The article is in review by Geochimica et Cosmochimica Acta.

235

6) Steps 1-5 are repeated until the number of samples within the Monte Carlo re-sampled dataset $>1$ million.

Step 3 is necessary because the bootstrap subset must have a continuous distribution. We used an analytical uncertainty of $2 \%$, as suggested by Keller and Schoene (2012). To test the effect of this choice of analytical uncertainty, we did two additional test runs, one in which all elements had a $4 \%$ uncertainty, and one where major elements had $2 \%$ uncertainty and trace elements had $4 \%$. We found that this made almost no difference in the final bootstrapped averages of all elements, and the effect on the bootstrapped confidence intervals was small enough that it could not be visually observed on most bivariate plots.

\subsection{Calculating Confidence intervals for bootstrapped means}

For each bootstrapped mean, we also calculated a 95\% confidence interval (CI), using the

following: $\bar{x} \pm t \frac{\sigma}{\sqrt{n}}$, where $\bar{x}$ and $\sigma$ are the bootstrapped mean and standard deviation, and $t$ is the right-tail critical value for a student $t$ distribution at the 0.05 level. We use the original number of samples for $n$, not the number of samples in the Monte Carlo set (Keller et al., 2015). These CI calculations rely on the assumption of normality. However, even if the original data was not normally distributed, by the Central Limit Theorem, means of the Monte Carlo set will always be normally distributed due to the large number of samples selected.

\subsection{Testing the robustness of segmentation schemes}

Partitioning the arc should be done in a way that the segments are most geochemically dissimilar to one another, so that the compositions can be compared, and inferences can be made as to the causes for the differences. If two segments are relatively similar, then they should be combined. Thus, to test whether segments are geochemically distinct, we use a multivariate technique called the Hotelling's $\mathrm{T}^{2}$ test. This test is the multivariate equivalent of the Student's $\mathrm{t}$ test and is a "post-hoc test" that follows a multivariate analysis of variance (MANOVA). Hotelling's $\mathrm{T}^{2}$ test essentially evaluates whether the multivariate means ("mean vector") of two segments, are different enough in n-dimensional space to reject the null hypothesis that the two are the same. Before testing this, the variables (elements) are transformed by the MANOVA technique, such that the new transformed variables minimize the within-segment variation and maximize the between-segment variation. Thus, instead of just simply comparing the multivariate distances between mean values of each segment, the Hotelling's $\mathrm{T}^{2}$ compares the 
This article is a non-peer reviewed preprint published at EarthArXiv.

The article is in review by Geochimica et Cosmochimica Acta.

265 means of each element, variance of each element, and multivariate covariance between elements (i.e. multivariate trends) of the data in each segment.

For large populations $(\mathrm{N}>30)$, such as the dataset in our study, the Hotelling's $\mathrm{T}^{2}$ statistic follows a $X^{2}$ distribution with $\mathrm{k}$ degrees of freedom, where $\mathrm{k}$ is the number of geochemical elements, allowing us to calculate a p value. Small $\mathrm{p}$ values indicate that two segments are more different than would be expected for two samples drawn from a single population. Specifically, if the $\mathrm{p}<0.05$, then we reject the null hypothesis, and the two segments are considered statistically distinct. The Mahalanobis distance, which is closely related to the Hotelling's $\mathrm{T}^{2}$, provides the multivariate distance between the mean vectors of the two groups. We used the Hotelling's $\mathrm{T}^{2}$ test on both the segmentation scheme of Schmidt et al. (2008) and our new statistically-based scheme and compared the Mahalanobis distances between segments to assess which created more distinct groups.

\subsection{Establishing new segments: modified Hierarchical clustering mechanism}

To determine a statistics-based segmentation scheme that best separates the Cascades arc into geochemically distinct regions, we developed a new, modified hierarchical clustering technique. For each step in a classic hierarchical clustering analysis, the two individuals or groups that are most similar (e.g. have the shortest distance between their mean values) are combined into a new group and this process is repeated until the desired number of groups are reached or all individuals are combined. Thus, the process clusters data such that the withingroup similarity is maximized. This process can be represented by a dendrogram, in which all individuals start out as separate branches on the y axis, and as two individuals are merged together, the distance between their means (distance of fusion) are shown on the $\mathrm{x}$ axis (Fig. 4). We had to modify this traditional hierarchical clustering technique to reduce sampling bias, deal with problems associated with missing data, ensure that clusters consisted of regions that were proximally close to one another, and account for correlation between elements (i.e. differentiation trends). These modifications will be discussed in further detail below.

To account for the significant covariation expected between many elements in geochemical data (e.g. correlation with $\mathrm{SiO}_{2}$ ) we chose to use the Mahalanobis distance (MD) as the measure of dissimilarity between groups in our hierarchical clustering method. In contrast to the more common centroid linkage approach, which uses Euclidian distance to measure the distance between clusters and assumes a spherical distribution for all elements around these centroids, 
This article is a non-peer reviewed preprint published at EarthArXiv.

The article is in review by Geochimica et Cosmochimica Acta.

296 MD measures the distance between the centroids of two groups while also considering the

297 dispersion around the centroids. This dispersion is measured by a dataset's covariance matrix.

298 The MD between groups $\mathrm{i}$ and $\mathrm{j}$ is given by: $M D_{i j}=\sqrt{\left(\bar{x}_{i}-\bar{x}_{j}\right)^{T} S^{-1}\left(\bar{x}_{i}-\bar{x}_{j}\right)}$ where $\mathrm{S}$ is the 299 covariance matrix and $\bar{x}_{i}$ is the mean vector for sample $\mathrm{i}$ that contains the means of each element.

300 To calculate the covariance matrix, we used the Monte Carlo bootstrapped dataset for each

301 latbin. Because most samples had data for only a subset of elements, missing data was common.

302 The covariance matrix of a dataset can become singular if it has excessive missing values. Thus,

303 in order to calculate the covariance matrix for our dataset, we used the Expectation Conditional

304 Maximization (ECM) algorithm of Meng and Rubin (1993) to calculate a non-singular

305 covariance matrix. This algorithm imputes values for these missing data, based on the mean and

306 variance of that element, and then iteratively changes these imputed values until the log-

307 likelihood function is maximized. Further explanation of the theory can be found in Little and

308 Rubin (2014).

309 We wanted to reduce the effects of sampling bias when creating our new segments. Thus, 310 every time two groups of latbins were combined, we performed a new Monte Carlo analysis with 311 bootstrap re-sampling to find that new group's bootstrapped mean elemental concentrations. This 312 portion of our procedure was almost identical to the one described above in section 3.2.

To create the clusters (segments), we used mafic data because primitive data are

314 relatively sparse in some parts of the arc (Schmidt et al., 2008). We also chose to exclude rear-

315 arc data, because this allows us to focus on the processes that may be responsible for along-strike

316 variability, without adding complications from the additional processes involved in rear-arc 317 magma generation.

318 We completed the clustering process in two stages. The initial stage was used to combine 319 the seven latbins with little to no data for some elements $(n<4)$ with the neighboring latbin that 320 was more similar. Since Mahalanobis distances are highly skewed by data with few observations, 321 we used only the 15 elements for which all latbins had at least 4 analyses, for this initial stage. 322 After merging those sparsely-sampled latbins with a neighbor, there were 25 elements for which 323 there were at least 4 analyses in all latbins of data. Thus, we completed the second stage of 


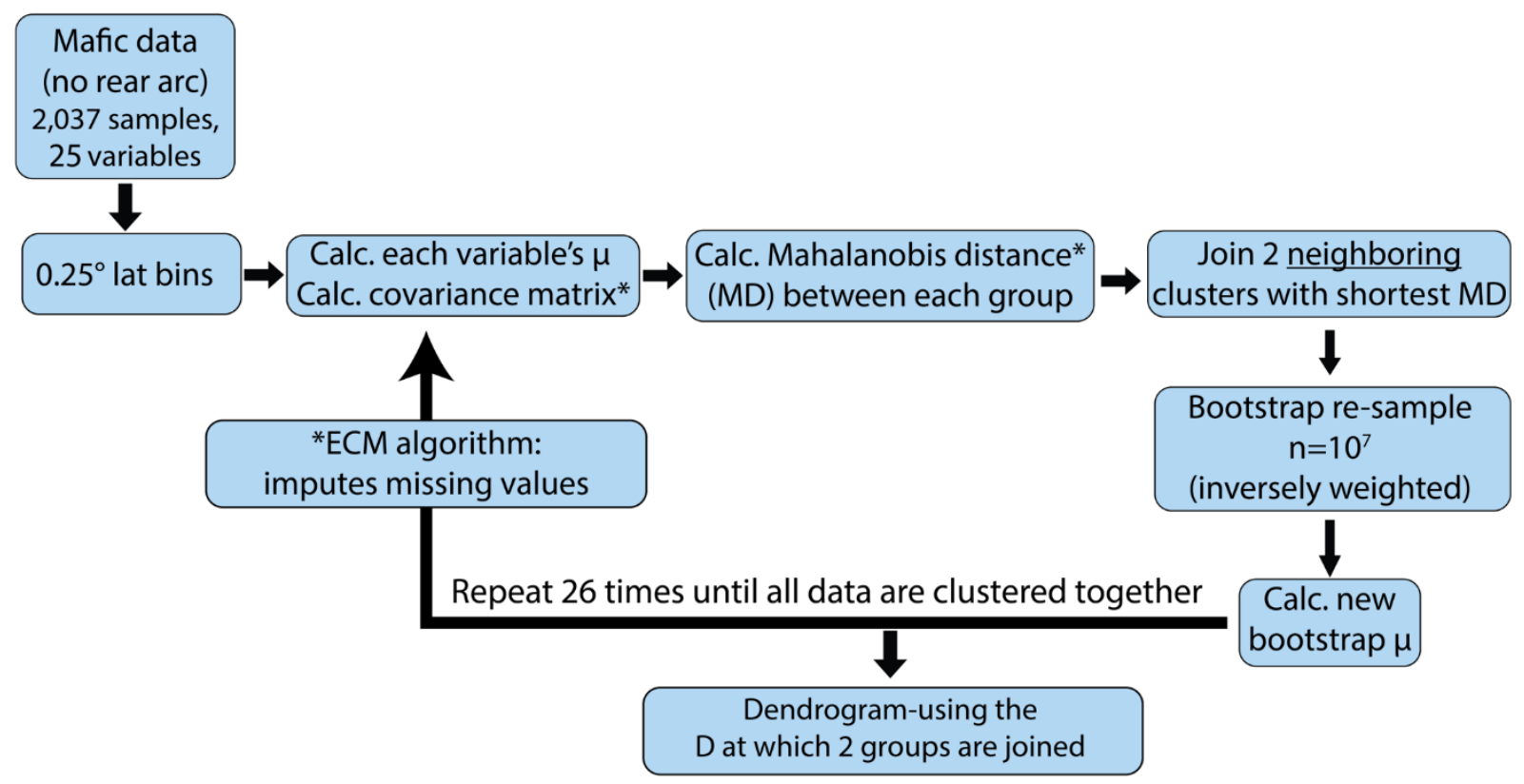

Figure 2: Flowchart of the new modified hierarchical clustering methodology developed in this study. Note that this methodology was completed in two stages, one with 15 elements to combine the sparsely sampled latbins, and the second with 25 elements.

324 clustering using these 25 elements. We wrote a MATLAB script for our modified hierarchical 325 clustering technique, which is summarized in Figure 2.

To objectively determine the step at which to end the clustering, we use the upper-tail 327 stopping rule of Mojena (1977). This rule states that the clustering should be cut when, for the 328 first time, $\alpha_{j+1}>\bar{\alpha}+k\left(s_{\alpha}\right)$, where $\bar{\alpha}$ and $s_{\alpha}$ are the mean and standard deviation of all the $\mathrm{j}$ 329 previous distances of fusion. The $\mathrm{k}$ value is the upper-tail critical value for a t distribution that is defined by the number of original separate groups, and a choice in confidence level. Since we 331 start with 25 separate latbins in the second round of clustering (after combining the ones with 332 little to no data), the critical $t$ value at the $97.5 \%$ confidence level is 2.064 . In other words, we 333 stopped the hierarchical clustering once the "closest" segments are separated by a MD that is $334\left(2.064 * s_{\alpha}\right)$ higher than the average of all previous steps' distance of fusion. Appendix 2. 
This article is a non-peer reviewed preprint published at EarthArXiv.

The article is in review by Geochimica et Cosmochimica Acta.

\subsection{Statistical test of the previous segmentation scheme}

Our Hotelling's $\mathrm{T}^{2}$ tests indicate that all four of the segments defined by Schmidt et al. (2008)are statistically distinct for mafic and primitive compositions (Table 2); for all neighboring segments, $\mathrm{p}<<0.05$. Bootstrapped MD values range from 2.5 to 3.1 for mafic compositions and 2.3 to 4.4 for primitive compositions. These MDs indicate that for mafic and primitive compositions, the Central and South Segments are less distinct than the other pairs $(\mathrm{MD}=2.5$ and 2.31, respectively). The North and Columbia Segments are most dissimilar with MD values of 3.1 and 4.4 for mafic and primitive compositions, respectively.

\subsection{The new statistically-derived segmentation scheme}

Using our modified

hierarchical clustering

technique, we establish a new

statistically-based segmentation

scheme for the Cascades arc

(Fig. 4). Based on the upper tail

stopping rule of Mojena

(1977), we terminate the

second stage of clustering after

12 steps (Fig. 3), at which point

the Mahalanobis distance of

fusion (4.9) exceeded the

critical value (4.8). At this

step, we have six clusters of

data, with MD values that range

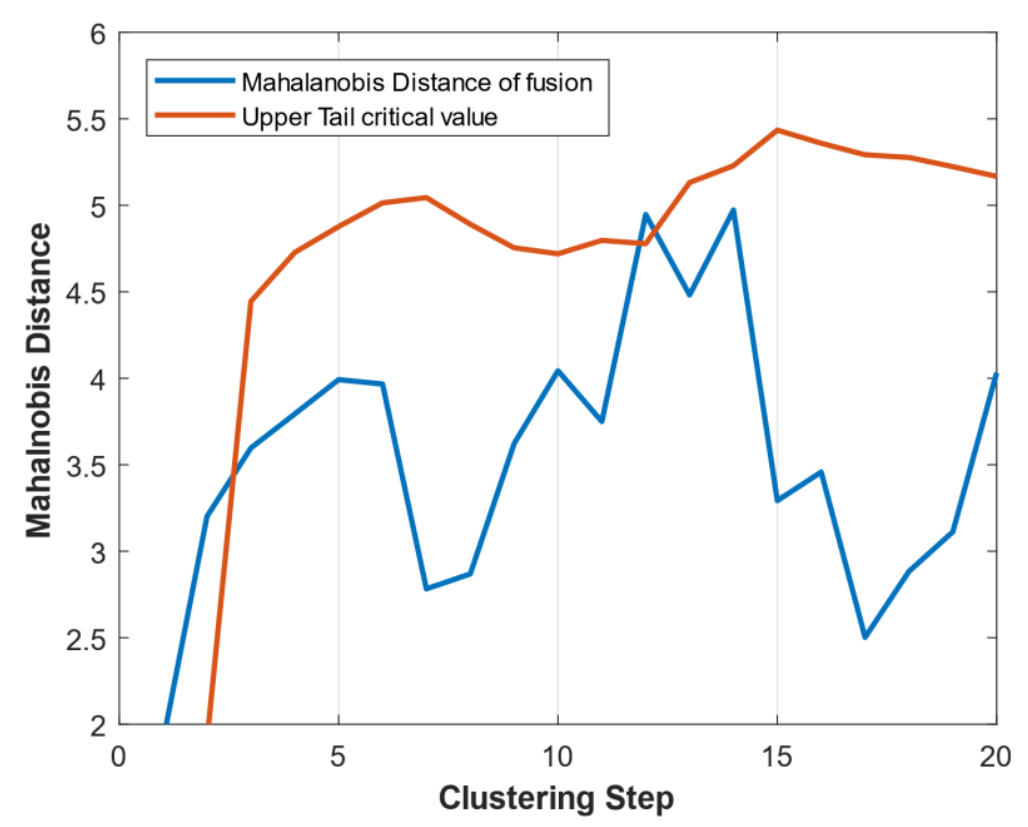

Figure 3: Methodology used to determine the step at which to end the hierarchical clustering. The Upper-tail stopping rule of Mojena (1977) states that we should end the clustering after the $12^{\text {th }}$ step, as that is the first time that the MD of fusion (blue line) is greater than the critical value (red line).

between 3.3 and 15.9. Cutting the clustering process at this step leaves one solitary latbin, the region that includes the Columbia River $\left(45.5-45.75^{\circ} \mathrm{N}\right)$, without a cluster. To avoid an unusual segment that spans only a quarter degree latitude and includes only 25 samples, we chose to add it to the cluster to the south, as it produces larger MD between the two neighboring segments $(\mathrm{MD}=3.6)$ than if we had added it to the north $(\mathrm{MD}=3.1)$. 
This article is a non-peer reviewed preprint published at EarthArXiv.

The article is in review by Geochimica et Cosmochimica Acta.

Thus, we propose a new scheme for the Cascades arc with seven segments, hereafter referred to as the Garibaldi $\left(49.75-51^{\circ} \mathrm{N}\right)$, Baker $\left(48.5-49.75^{\circ} \mathrm{N}\right)$, Glacier Peak $\left(47.75-48.5^{\circ} \mathrm{N}\right)$, Washington $\left(45.75-47.75^{\circ} \mathrm{N}\right)$, Graben $\left(44.25-45.75^{\circ} \mathrm{N}\right)$, and South $\left(41.25-44.25^{\circ} \mathrm{N}\right)$ Segments (Fig 4). Hotelling's $\mathrm{T}^{2}$ tests indicate that for all compositions, $\mathrm{p}<<0.05$, and thus, these new segments are all statistically distinct from each other (Table 2). MD values for mafic compositions range between 3.6 and 16.0, with the largest difference between the Baker and Glacier Peak Segments (MD=16.0) and Garibaldi and Baker Segments (MD=10.0). The smallest distinction is between Washington and Graben Segments, with a MD of 3.6.

Table 2: Hotelling's $\mathrm{T}^{2}$ test results for neighboring segments of our new segmentations scheme (left) compared to those of Schmidt et al., 2008. We used the same data for each scheme and used the same Monte Carlo bootstrap methods. All neighboring segments have $\mathrm{p}<<0.01$, indicating that both schemes create statistically distinct segments. However, $\mathrm{T}^{2}$ values, F-values, and Mahalanobis distances (MD) between segments are much higher in the new scheme indicating that it creates more statistically distinct segments.

\begin{tabular}{|r|ccccc|ccc|}
\cline { 2 - 9 } \multicolumn{1}{c|}{} & \multicolumn{5}{c|}{ New Segments } & \multicolumn{3}{c|}{ Schmidt et al., 2008 } \\
\cline { 2 - 9 } & Garibaldi & Baker & GP vs. & WA vs. & Graben & North vs. & Columbia & Central \\
& vs. Baker & vs. GP & WA & Graben & vs. South & Columbia & vs. Central & vs. South \\
\hline $\mathrm{n}$ & 157 & 98 & 686 & 887 & 1,191 & 1,035 & 1,565 & 999 \\
$\mathrm{MD}$ & 10.0 & 16.0 & 7.3 & 3.6 & 4.5 & 3.1 & 2.6 & 2.5 \\
$\mathrm{~T}^{2}$ & 3,142 & 6,229 & 2,671 & 2,392 & 4,124 & 1,651 & 2,678 & 1,244 \\
$\mathrm{~T}^{2}$ critical & 40 & 40 & 40 & 40 & 40 & 40 & 40 & 40 \\
$\mathrm{~F}$ & 97 & 169 & 95 & 86 & 149 & 60 & 98 & 45 \\
F critical & 1.6 & 1.6 & 1.5 & 1.5 & 1.5 & 1.5 & 1.5 & 1.5 \\
p-value & $<<0.01$ & $<<0.01$ & $<<0.01$ & $<<0.01$ & $<<0.01$ & $<<0.01$ & $<<0.01$ & $<<0.01$ \\
\hline
\end{tabular}

\section{Discussion}

\subsection{Comparison of segmentation schemes}

The primary objective of partitioning the arc into segments is to explore the causes for the geochemical differences between them. Thus, it is most useful if the partitioning is done such that the geochemical differences between segments is maximized. Although the segments defined by Schmidt et al. (2008)are statistically different from each other, our new statisticallyderived segments are up to 6.3 times more geochemically distinct than the previous version. Thus, our new objective scheme better maximizes the differences between neighboring segments and is therefore better suited for partitioning the arc for compositional comparisons.

The new segmentation also provides new insight into longstanding issues related to Cascades arc volcanism and magma sources. For example, the marked change in the strike of the 
This article is a non-peer reviewed preprint published at EarthArXiv.

The article is in review by Geochimica et Cosmochimica Acta.

arc near Mount Baker and Glacier Peak are typically used to colloquially subdivide the arc into 2015), however, the border between these portions of the arc is point of contention that may be resolved by our objective statistical approach. Recent high precision $\mathrm{Sr}, \mathrm{Nd}, \mathrm{Pb}$, and $\mathrm{Hf}$ isotopic

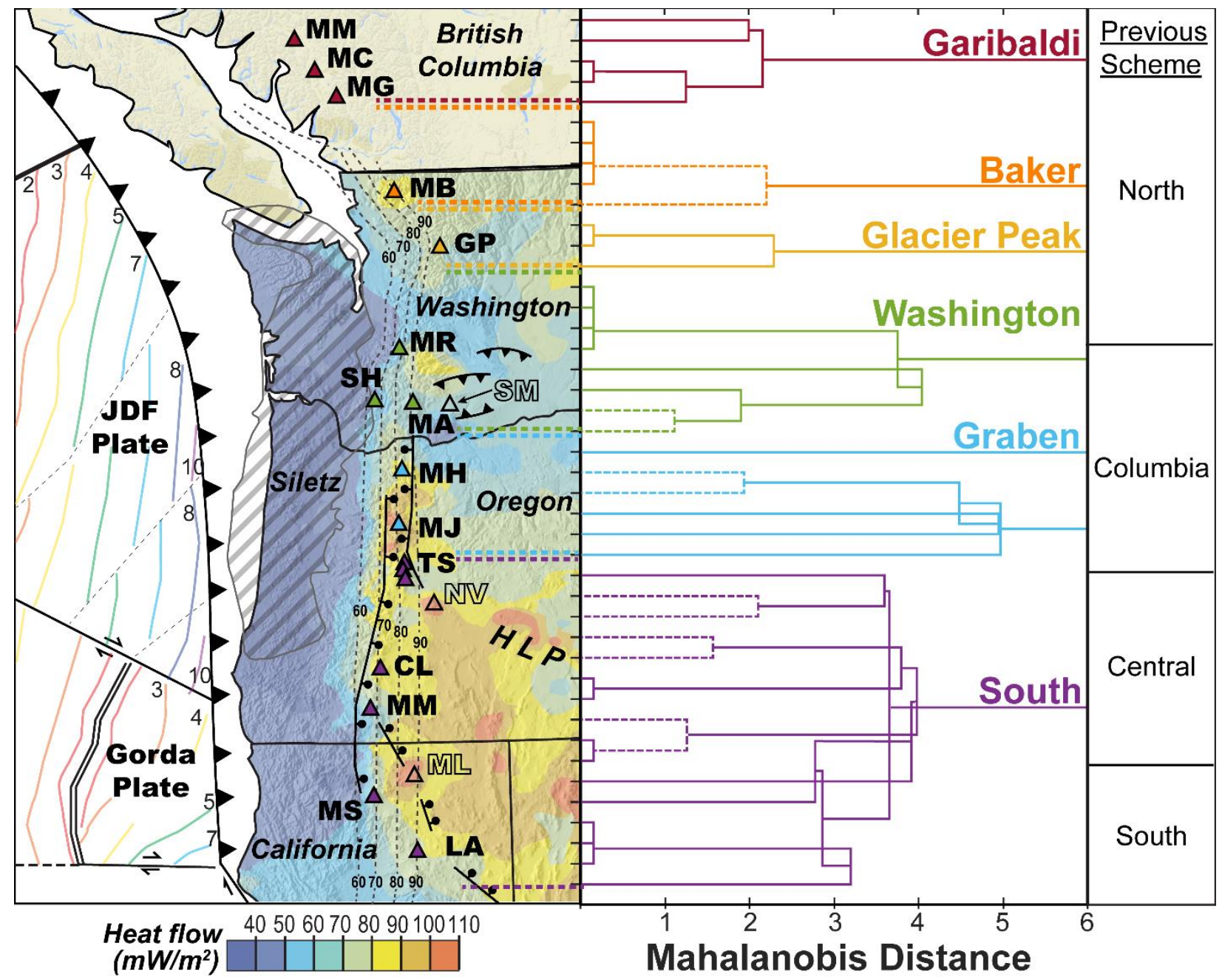

Figure 4: Dendrogram (right) showing the MD at which each latbin was clustered during the modified hierarchical clustering. Latbins that were combined in the first round of clustering (15 elements) are designated by dashed lines. In some cases, after a new cluster was formed at a higher MD, the resulting cluster became more similar to another and was then combined at a lower MD than the prior step. This leads to crossing dendrogram branches. Final segments are designated by color and can be compared to the previous scheme of Schmidt et al. (2008) on the far right. The map (left) summarizes various along-strike differences that may lead to compositional variability of the Cascades arc. Approximate age of Juan de Fuca (JDF) and Gorda plates, shown as colored lines, are from Wilson (2002). Estimated extent of the Siletz Terrain is from Phillips et al. (2017). Heat flow data is from Ingebritson and Mariner (2010). Depth of the subducting slab is estimated by McCrory et al. (2012). General locations of major faults are from Schmidt et al. (2008). General location of the High Lava Plains (HLP) is also shown. Major stratovolcanoes are shown with triangles, colored by the new segmentation scheme. From north to south: Mount Meager (MM), Mount Cayley (MC), Mount Garibaldi (MG), Mount Rainier (MR), Mount St. Helens (SH), Mount Adams (MA), Mount Hood (MH), Mount Jefferson (MJ), Three Sisters (TS), Crater Lake/Mazama (CL), Mount McLoughlin (MM), Mount Shasta (MS), and Lassen Peak (LA). Rear-arc volcanoes, including Simcoe volcanic field (SM), Newberry (NV), and Medicine Lake (ML), which were not used to create the new scheme, are shown as empty triangles. 
This article is a non-peer reviewed preprint published at EarthArXiv.

The article is in review by Geochimica et Cosmochimica Acta.

393 work finds significant differences between the Garibaldi and Cascades arcs and suggests that they are fed by isotopically distinct mantle sources and should thus be considered separate arc segments (Mullen et al., 2017). Our study, which utilizes a much larger major and trace element

396 dataset agrees with this distinction, showing statistically significant differences between the 397 Garibaldi volcanic belt (north of the US-Canada border) and the High Cascades to the south. 398 While multiple studies consider Glacier Peak to be part of the Garibaldi belt (Hildreth, 2007; 399 Schmidt et al., 2008; Mullen and Weis, 2015), Mullen et al. (2017) choose to reclassify it to be 400 part of the High Cascades based on isotopic data. However, our results indicate that Glacier Peak and Mount Baker are compositionally distinct from both the Garibaldi Segment and the Washington Segment of the High Cascades to the south, as well as from each other. In fact, these are the most statistically distinct portions of the $\operatorname{arc}(\mathrm{MD}=16$ and $\mathrm{MD}=10)$. This distinction is important as it implies that these two transition volcanoes result from different processes or source conditions than those to both the north and the south; this will be explored further in the 406 following section.

In addition to considering Mount Baker and Glacier Peak to be disparate segments, our scheme differs from that of Schmidt et al. (2008) by several other key features. Our results indicate that volcanic rocks north of the Columbia river (Washington Segment) and those south of the river are statistically distinct from one another $(\mathrm{MD}=3.6)$, despite having been grouped together within the Columbia Segment of the previous study (Fig. 4). Furthermore, because we used a comprehensive dataset that includes data from the many smaller mafic vents between the major stratovolcanoes, we can better define the boundaries between all segments. For example, while mafic rocks in the vicinity of Mount Rainier were not included within any segment by the 415 previous study, our results indicate that they are statistically more similar to those to the south and can therefore be considered part of the Washington Segment. Finally, although Schmidt et

417 al. (2008) drew a boundary near the Oregon-California border based on data from rear-arc 418 Medicine Lake, there was no data from the over 70 vents (Hildreth, 2007) located within the 140 419 km region between Crater Lake and Medicine Lake. Our study, which utilizes nearly 200 420 samples from that region, finds that they are statistically similar to those that surround Crater 421 Lake. In fact, we find that bootstrapped mean compositions of all latbins from Lassen Peak to the 422 Three Sisters Region are similar enough to warrant placing them within the same segment (Fig. 423 4). 
This article is a non-peer reviewed preprint published at EarthArXiv.

The article is in review by Geochimica et Cosmochimica Acta.

424

425

426

427

428

429

430

431

432

433

434

435

436

437

438

439

440

441

442

443

444

445

446

447

448

449

450

451

452

453

454

We also note that whereas Schmidt et al. (2008) used data from rear-arc volcanoes to partition the arc, our study chose to exclude these data. This continues a longstanding pattern in the Cascaded where many authors consider Simcoe, Newberry, and Medicine Lake to be rear-arc or back-arc volcanoes that should be distinguished from those the arc-front (Hildreth, 2007; Donnelly-Nolan et al., 2008; Long et al., 2012), but others treat these as part of the arc-front (Guffanti and Weaver, 1988; Blakely et al., 1997; Schmidt et al., 2008; Mullen et al., 2017). Our Hotelling's $\mathrm{T}^{2}$ tests indicate that all three are statistically dissimilar than the adjacent arc-front segments that lie to the west, with bootstrapped MD values of 4.2, 3.6, and 4.0 for Simcoe, Newberry and Medicine Lake, respectively. Thus, we suggest that future regional studies treat these as rear-arc volcanic centers that have significantly different compositions, and thus processes of magma generation, compared to the adjacent arc-front volcanoes.

\subsection{Compositional differences between segments}

By calculating the bootstrapped means of our comprehensive dataset, we have removed significant sampling bias and therefore established mean compositions that best represent each of our new arc segments as a whole. From this we can explore the bulk compositional differences between each arc segment and infer better the regional processes affecting them, rather than local processes at individual volcanoes. Although previous studies have explored the causes of compositional variability within the Cascades arc (e.g. Bacon et al., 1997; Green and Harry, 1999; Leeman et al., 1990, 2005; Mullen and Weis, 2015; Schmidt et al., 2008), our study differs in that we are examining differences between the unbiased mean compositions of statistically distinct segments to elucidate causes for these differences.

\subsubsection{Distribution of primitive Cascades arc endmembers}

Several end-member primitive basalt compositions have been proposed for the Cascades including arc-typical calc-alkaline basalts (CABs), low-K tholeiites (LKTs) (sometimes referred to as high alumina olivine tholeiite; e.g. Bacon et al., 1997; HART et al., 1984), and intraplatetype basalts (IPBs) (sometimes called ocean island, within-plate, or HFSE-type basalts; e.g. Conrey et al., 1997; Schmidt et al., 2008). A detailed description of each of these Cascades arc end-members is given in Mullen et al. (2017). The differing major and trace element compositions of these endmembers are suggested to be the result of different mantle processes or 
This article is a non-peer reviewed preprint published at EarthArXiv.

The article is in review by Geochimica et Cosmochimica Acta.

455 compositions (Leeman et al., 1990; Bacon et al., 1997; Conrey et al., 1997; Leeman et al., 2005;

456 Schmidt et al., 2008; Rowe et al., 2009; Mullen et al., 2017; Carlson et al., 2018). Although these

457 studies have demonstrated that all endmember compositions exist within each portion of the arc,

458 no previous study has ascertained the relative proportion of these compositions using a

459 comprehensive dataset that is statistically treated to mitigate sampling bias.

460 We classified 628 of the 1,064 primitive samples in our dataset based on the

461 compositional definitions (Table 3) given in Schmidt et al. (2008) and Leeman et al. (2005).

462 Many samples were mixtures of the endmembers and could not be definitively classified as a

463 single endmember type. One common mixture were basalts that had LKT-like low $\mathrm{K}_{2} \mathrm{O}(<0.4$

464 wt.\%) and $\mathrm{K}_{2} \mathrm{O} / \mathrm{TiO}_{2}(<0.4)$ but were enriched in subduction fluid-mobile elements such as $\mathrm{Ba}$

465 and $\mathrm{Sr}$ similar to CABs. Due to their abundance, we chose to create a separate category of

466 "High-Ba LKTs" when calculating proportions.

Table 3: Criteria used to classify primitive samples into Cascades endmembers. Similar criteria were used by Leeman et al. (2005) and Schmidt et al. (2008).

\begin{tabular}{r|cccccc} 
Primitive Type & $\mathrm{K}_{2} \mathrm{O}$ & $\mathrm{K}_{2} \mathrm{O} / \mathrm{TiO}_{2}$ & $\mathrm{Ba} / \mathrm{Nb}$ & $\mathrm{Sr} / \mathrm{Y}$ & $\mathrm{Nb} / \mathrm{Zr}$ & $(\mathrm{K} / \mathrm{Nb})_{\mathrm{N}}$ \\
\hline $\mathrm{CAB}$ & $>0.5$ wt.\% & $>0.4$ & $>20$ & $>15$ & $<0.09$ & $>0.2$ \\
High-Ba LKT & $<0.5$ wt.\% & $<0.4$ & $>20$ & & $<0.09$ & $>0.2$ \\
LKT & $<0.5$ wt.\% & $<0.4$ & $<20$ & $<20$ & $<0.09$ & $>0.2$ \\
IPB & $>0.25$ wt. $\%$ & $>0.4$ & $<20$ & & $>0.08$ & $<0.25$
\end{tabular}

Utilizing the Monto Carlo bootstrap methodology to remove sampling bias, we observe

468 significant inter-segment differences in the distribution of primitive lava types (Fig. 5). The

469 Garibaldi Segment consists almost entirely (86\%) of IPB-type basalts, while these are

470 completely absent in the Baker and Glacier Peak Segments. In these latter two, more arc-typical

471 CAB-types are most common (75\% and 62\%, respectively). IPB-type basalts are also relatively

472 common in the Washington (37\%) and Graben Segments (33\%). True LKT basalts are entirely

473 absent in the northern portion of the Cascades and Garibaldi Segment and become quite common

474 in the southern half of the arc, which is undergoing overall extension (Wells et al., 1998;

475 McCaffrey et al., 2007). This extension, which is likely also responsible for higher heat flow in 476 the southern arc (Fig. 4) may also allow more decompression-driven LKT-type melts form and 477 erupt (Schmidt et al., 2008; Ingebritsen and Mariner, 2010; Mullen et al., 2017). 


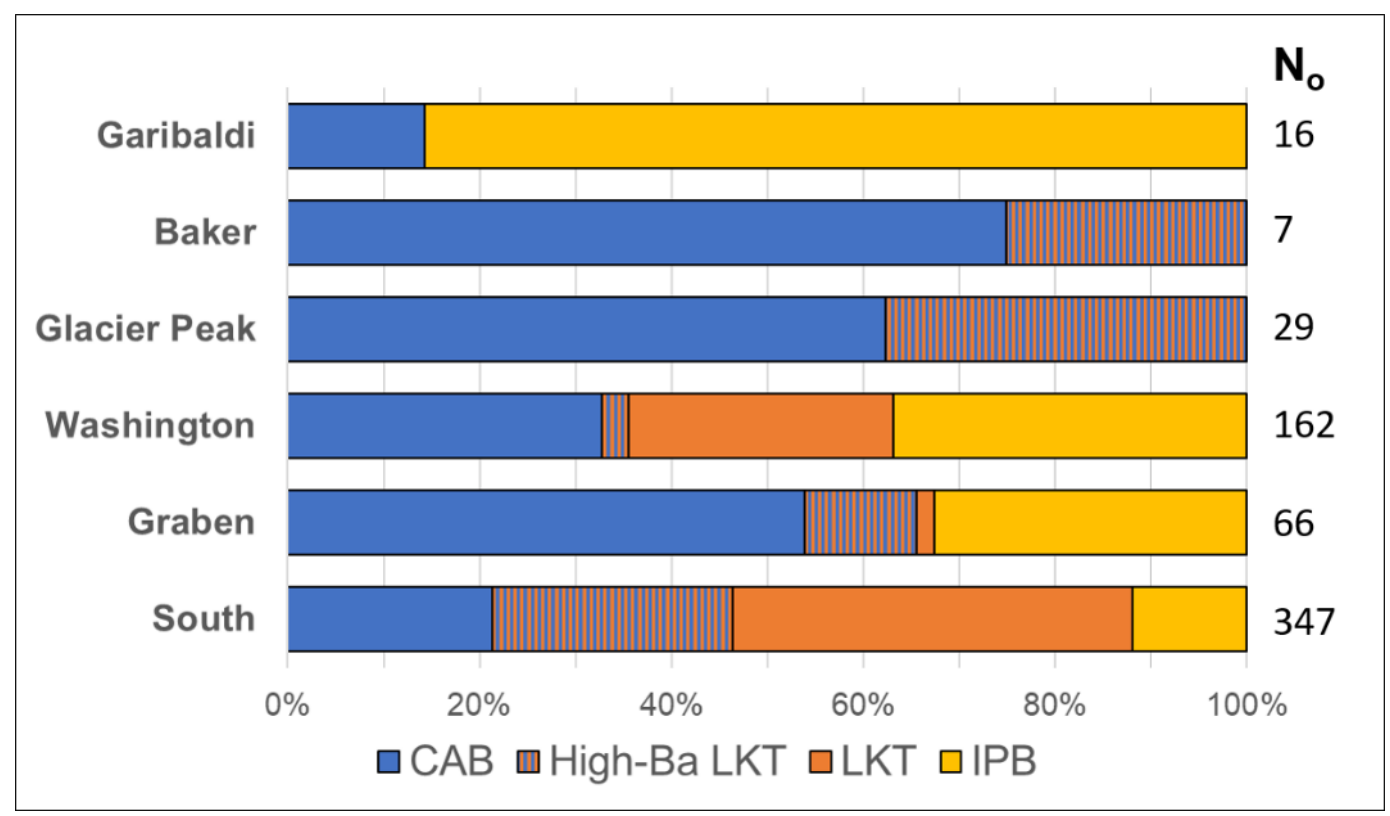

Figure 5: Posterior distribution of primitive lava types for the new segments. The total number of samples in the prior dataset $\left(\mathrm{N}_{\mathrm{o}}\right)$, are shown on the right.

While some authors suggest that the mantle beneath the Cascades may be inherently heterogenous (e.g. Bacon et al., 1997), Mullen et al. (2017) find that there are no isotopic differences between these endmembers and suggest an isotopically homogeneous mantle source for all endmember types. Reiners et al. (2000) and Rowe et al. (2009) demonstrate that Cascades CABs and LKTs can both be produced from the same initial composition, simply by varying the flux of fluids and degree of melting. Thus, compositional differences between Cascades arc endmembers are likely to be primarily the result of differing processes of mantle melting and variable degrees of modification by the subduction components (Mullen et al., 2017).

In addition to comparing the relative proportions of these endmembers, our study allows us to compare the bootstrapped mean compositions, which can be thought of as a representation of the unbiased bulk mixture of various primitive lava types, and thus, the relative contributions of the process that lead to their formation. In addition, our Monte Carlo approach allows us to calculate confidence intervals of these mean compositions which provides the unique opportunity to examine both the inter-segment differences in mean compositions and the unbiased variance in compositions within each segment. In the following sections we will explore these differences with respect to subduction fluid contribution, depth and processes of 
This article is a non-peer reviewed preprint published at EarthArXiv.

The article is in review by Geochimica et Cosmochimica Acta.

\subsubsection{Subduction fluid signature}

The Glacier Peak, Mount Baker and South Segments demonstrate the largest influence of fluid-flux melting. These are each characterized by an arc-typical negative $\mathrm{Nb}$ and $\mathrm{Ta}$ anomaly (Fig. 6), as well as a relative enrichment in LILE, such as high $\mathrm{Sr} / \mathrm{P}, \mathrm{Ba} / \mathrm{Nb}$ (Fig. 7) and $\mathrm{Ba} / \mathrm{Ce}$, which have been shown to be good indicators of the influence of slab fluids (Pearce, 1982; Borg et al., 1997; Pearce and Stern, 2006; Ruscitto et al., 2010). Intense fracturing and internal deformation of the subducting Gorda Plate due to motion along the Mendocino Fracture Zone (Wilson, 2002) may lead to increased fluid penetration and higher delivery of subduction fluids into the South Segment (Grove et al., 2003; Schmidt et al., 2008). Other studies have previously demonstrated the more hydrous nature of lavas and melt inclusions near Lassen Peak (Borg et al., 1997) and Mount Shasta (Sisson and Layne, 1993; Grove et al., 2002). It has also been suggested, based on radiogenic $\mathrm{Sr}, \mathrm{Nd}$, and $\mathrm{Pb}$ isotopes in these primitive lavas, that some of the fluid-flux signature could be from prior metasomatism of the mantle by much older subduction fluids (Borg et al., 1997; Borg et al., 2002; Carlson et al., 2018). Subduction rates were much

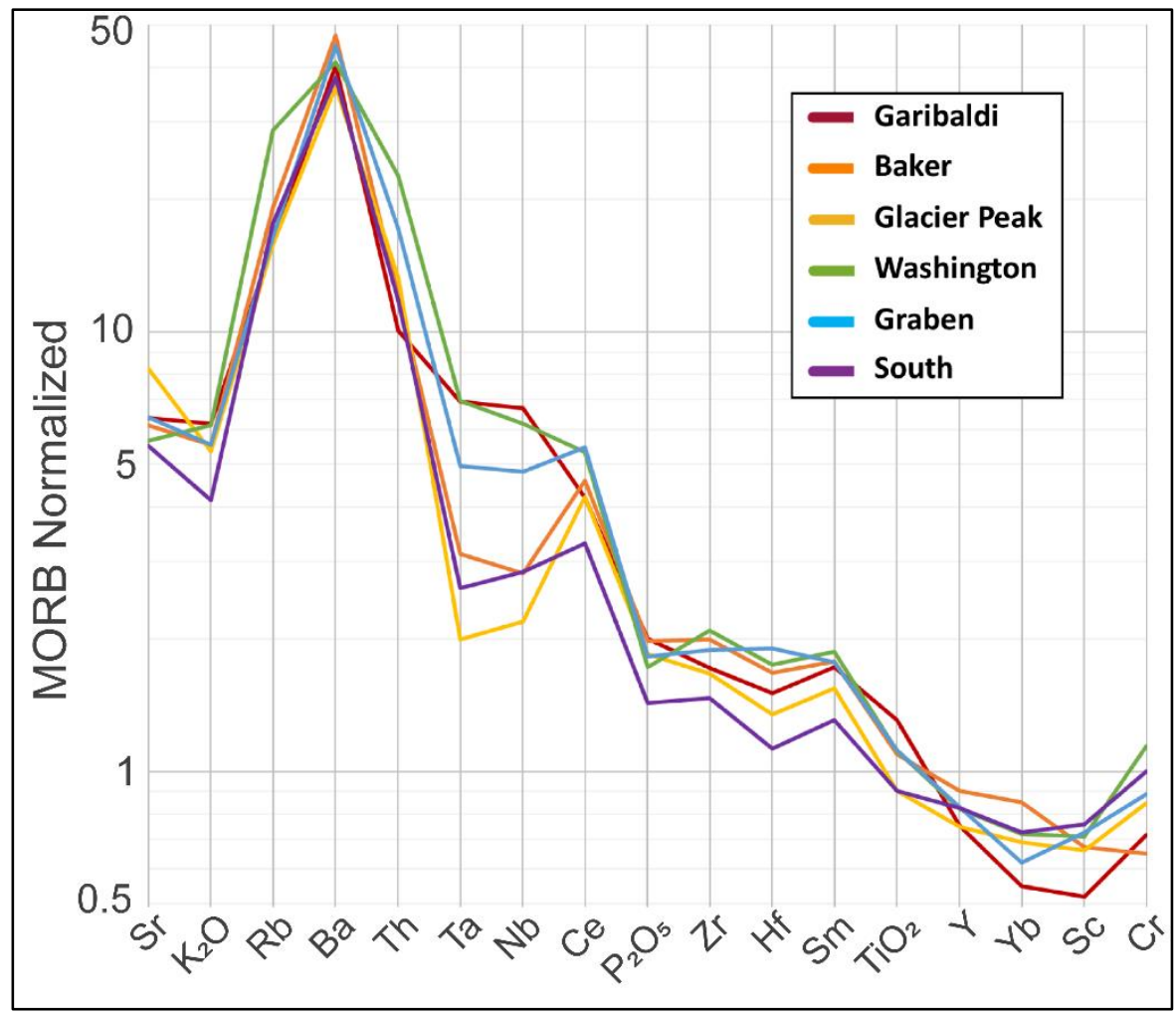

Figure 6: "Spider diagram" showing the MORB-normalized (Pearce, 1983) bootstrapped mean concentrations of minor and trace elements. For clarity, confidence intervals are not shown. However, trace element differences discussed in the text are statistically significant. Segment color scheme is the same as in Fig. 4. 
This article is a non-peer reviewed preprint published at EarthArXiv.

The article is in review by Geochimica et Cosmochimica Acta.

510 faster in the past (Verplanck and Duncan, 1987), which would have caused sufficient heating and

511 dehydration of the slab to take place further inboard of the subduction zone (Leeman et al.,

512 2005).

513 In addition, the South Segment may record the largest degree of mantle melting, as it has

514 the flattest REE and thus lowest $\mathrm{Ce} / \mathrm{Yb}$ (Fig. 7), which is in stark contrast to the neighboring

515 Graben Segment, that has the steepest REE pattern (Fig. 8). This is consistent with

516 thermobarometry results of Ruscitto et al. (2010) that indicate higher degrees of partial melting

$517(>20 \%)$ of a more hydrous source $\left(>0.7\right.$ wt. \% $\left.\mathrm{H}_{2} \mathrm{O}\right)$ in the Mount Shasta region compared to

518 volcanoes of the Graben Segment (9-11\% melting, 0.4-0.56 wt. \% $\mathrm{H}_{2} \mathrm{O}$ ). The relatively flat

519 REE patterns of the South Segment are not likely to be simply the result of shallower melting, as

520

HREE and Y abundances are similar to Graben segment, and previous studies have shown

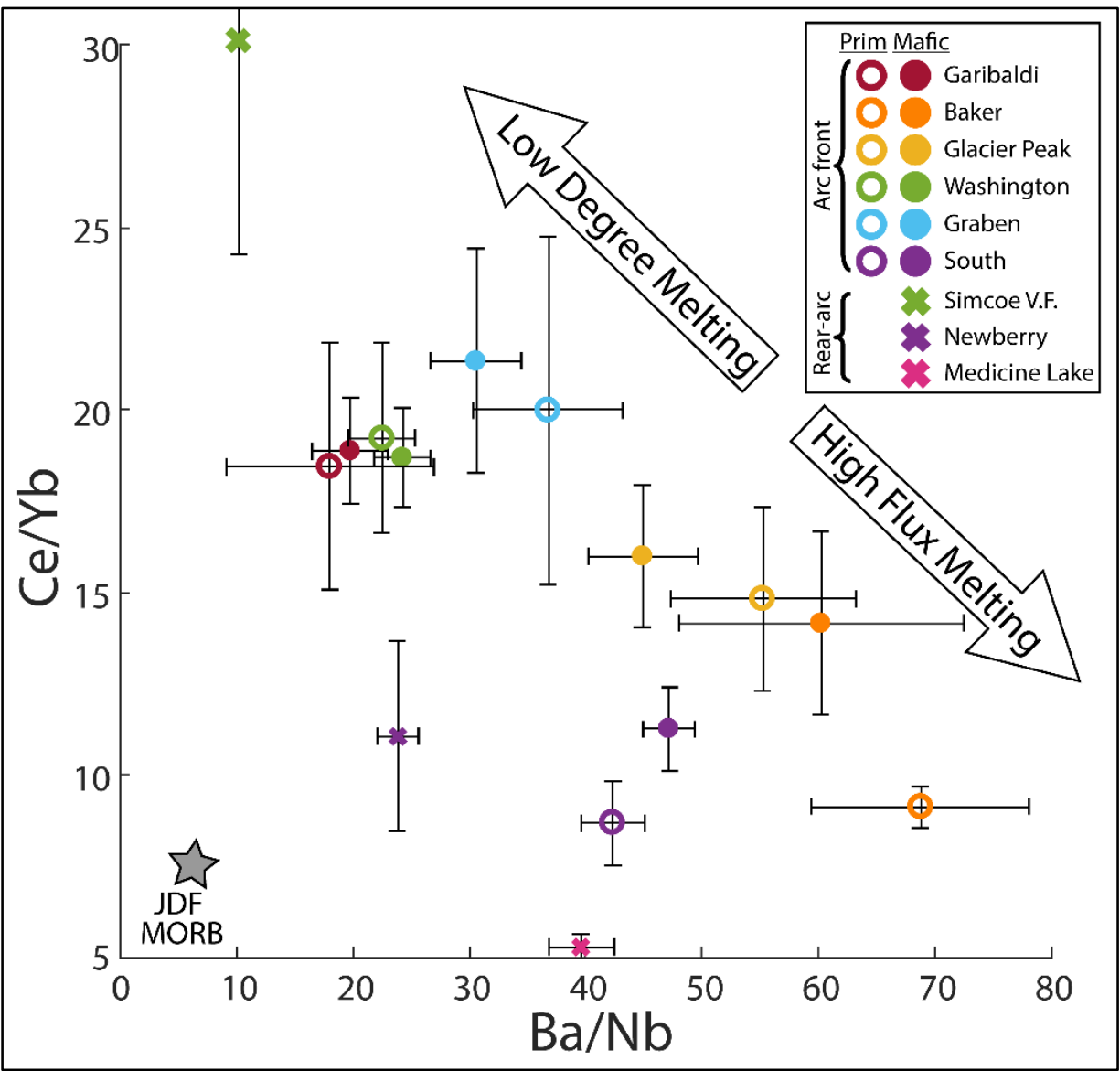

Figure 7: $\mathrm{Ba} / \mathrm{Nb}$ vs. $\mathrm{Ce} / \mathrm{Yb}$ diagram of bootstrapped mean values and $95 \%$ confidence intervals for primitive (open circles) and mafic (closed) compositions of the new segments. Mafic compositions for rear-arc volcanoes are also shown by the x symbol. The mean value for Juan de Fuca MORB (Gill et al., 2016) is also shown. Gorda MORB has $\mathrm{Ce} / \mathrm{Yb}$ value (3.5) that could not be shown on this scale. 
This article is a non-peer reviewed preprint published at EarthArXiv.

The article is in review by Geochimica et Cosmochimica Acta.

521 similar melt segregation depths for volcanoes from these two segments (Elkins Tanton et al.,

522 2001; Leeman et al., 2005; Ruscitto et al., 2010; Till et al., 2013). Furthermore, magnetotelluric

523 (MT) studies indicate that the southern portion of the arc exhibits the highest supra-slab MT

524 resistivity, interpreted to be the highest degree of flux melting in the Cascades arc (Wannamaker

525 et al., 2014).

526 Primitive lavas from the Glacier Peak region are the most enriched in $\mathrm{Sr}, \mathrm{Th}, \mathrm{U}$, and $\mathrm{Pb}$,

527 both in terms of the elemental concentration, as well as in ratios where a high field strength

528 element such as $\mathrm{Nb}$ or $\mathrm{Ta}$ is the denominator. These particular elements have been demonstrated

529 to have fluid-rock partition coefficients that are highly temperature dependent, such that $\mathrm{Sr}$, $\mathrm{Th}$,

530 and $\mathrm{U}$ are fluid-immobile $\left(\mathrm{D}=0.3,0.1,0.1\right.$ respectively) at lower temperatures (i.e. $700^{\circ} \mathrm{C}$ at 4

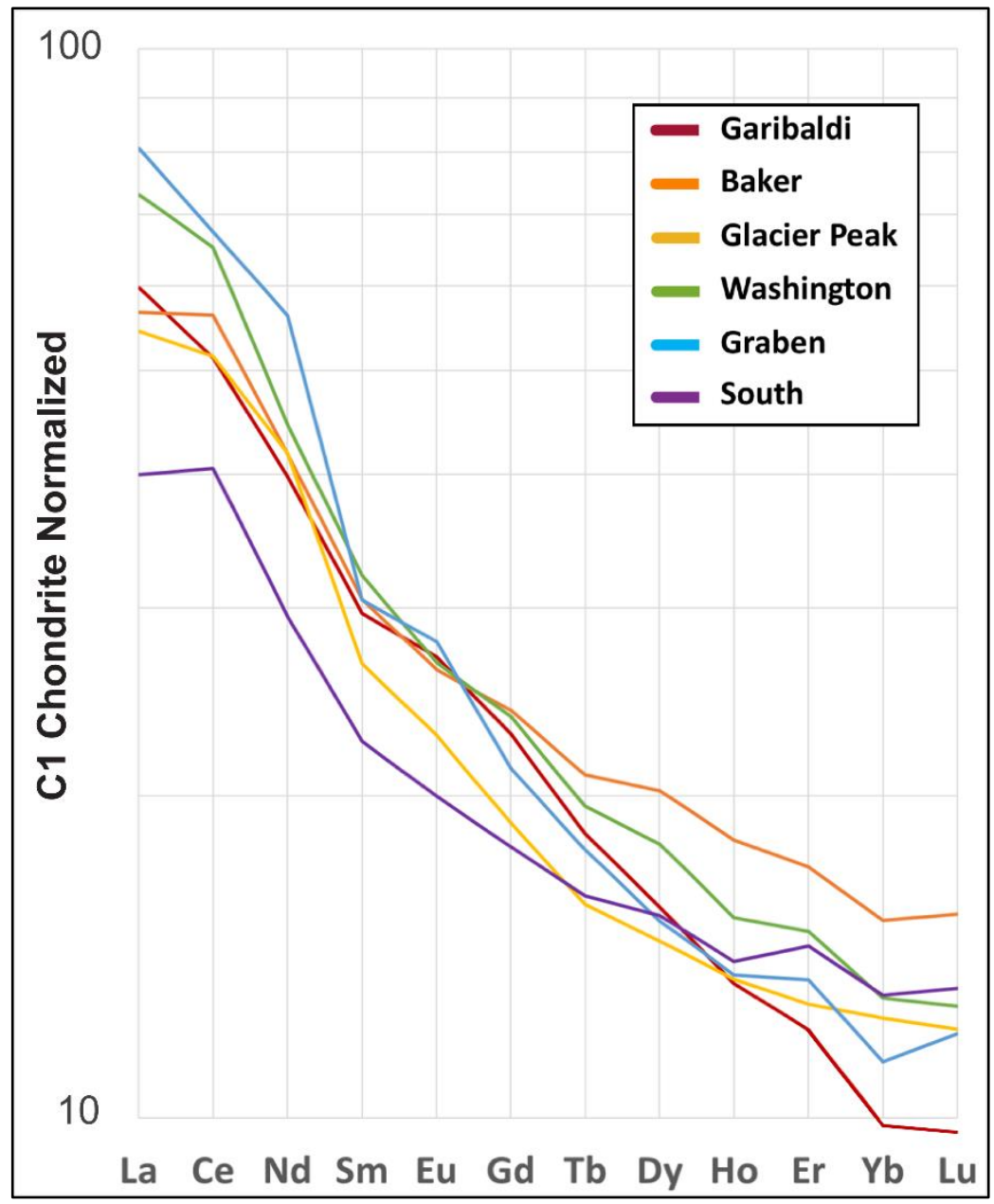

Figure 8: REE plot of the C1-Chondrite normalized (Sun and McDonough, 1989) bootstrapped mean values for the new segments. For clarity, confidence intervals are not shown. However, differences in REE discussed in the text are statistically significant. 
This article is a non-peer reviewed preprint published at EarthArXiv.

The article is in review by Geochimica et Cosmochimica Acta.

$531 \mathrm{GPa})$ but then become highly fluid-compatible ( $\mathrm{D}=22,23,17$, resp.) at higher temperatures

$532\left(1100^{\circ} \mathrm{C}\right)($ Kessel et al., 2005). Thus, the enrichment of these elements in Glacier Peak, which

533 lies further east than any other Cascades volcano, may be the result of the input of deeper and

534 hotter supercritical subduction fluids. In fact, McCrory et al. (McCrory et al., 2012) estimate that the volcano is situated approximately $95 \mathrm{~km}$ above the Juan de Fuca slab, whereas the neighboring volcanoes, Mount Baker and Mount Rainier are 80 and $70 \mathrm{~km}$ above the slab, respectively. This composition-depth relationship can also be seen at Medicine Lake, a southern rear-arc volcano that lies approximately $85 \mathrm{~km}$ above the slab (McCrory et al., 2012) and has higher $\mathrm{Th}, \mathrm{U}, \mathrm{Th} / \mathrm{Nb}$ and $\mathrm{Th} / \mathrm{Ta}$ than the arc-front South segment.

The Garibaldi Segment exemplifies the lowest fluid-flux signal in the arc (lowest $\mathrm{Ba} / \mathrm{Nb}$, $\mathrm{Th} / \mathrm{Nb}$, and high HFSE), which may result from the slab being young and hot (Wilson, 2002) which would cause dehydration of the slab significantly trench-ward of the arc (Schmidt et al., 2008). The Washington Segment also has a reduced fluid signature, lacking the arc-typical NbTa anomaly (Fig. 6) and the second lowest $\mathrm{Sr} / \mathrm{P}, \mathrm{Ba} / \mathrm{Nb}, \mathrm{Pb} / \mathrm{Ce}$, and $\mathrm{Th} / \mathrm{Ta}$ ratios.

Although the Graben Segment has a reduced fluid component compared to that of the Glacier Peak, Mount Baker, and South Segments, it does have a small Nb-Ta anomaly and significantly higher $\mathrm{Ba} / \mathrm{Zr}$ and $\mathrm{Sr} / \mathrm{P}$ than the neighboring Washington Segment. In addition, the Graben Segment has the highest primitive $\mathrm{Cs} / \mathrm{Rb}, \mathrm{K}_{2} \mathrm{O} / \mathrm{Rb}$, and $\mathrm{La} / \mathrm{Sm}$, indicating that there may be a larger contribution from subducted sediment (Labanieh et al., 2012), as offshore drill cores of Cascadia sediment have elevated values for these ratios (Carpentier et al., 2014). Furthermore, low $\mathrm{Pb} / \mathrm{Ce}$ indicates that the sediment contribution is likely as melt rather than aqueous fluid (Brenan et al., 1995; Kelemen et al., 2003), as Pb would be more strongly partitioned into the fluid. However, $\mathrm{Ce}$ does become more compatible than $\mathrm{Pb}$ in supercritical fluid at pressure $>6$ GPa and temperature above $1,000^{\circ} \mathrm{C}$ (Kessel et al., 2005). Our segmentation scheme places the boundary between the Graben and Washington Segments at the approximate latitude of the pole of rotation of the Cascades fore-arc block which causes overall compression in the Washington Segment and extension in the Graben Segment (Wells et al., 1998; McCaffrey et al., 2007; Labanieh et al., 2012). A marked increase in hydrothermal heat discharge and crustal heat flow (Fig. 4) south of $44.75^{\circ} \mathrm{N}$ latitude (near Mount Jefferson) is consistent with extensional stresses (Ingebritsen and Mariner, 2010) or increased flux of basalt and magmatic heat from the mantle. Extension in the Graben Segment has been suggested to induce decompression mantle melting 
This article is a non-peer reviewed preprint published at EarthArXiv.

The article is in review by Geochimica et Cosmochimica Acta.

562 (Conrey et al., 2002; Conrey, 2004) or focus upwelling mantle that is already undergoing

563

564

565

566

567

568

569

570

571

572

573

574

575

576

577

578

579

580

581

582

583

584

585

586

587

588

589

590

591

592 decompression melting directly into the arc (Till et al., 2013). We propose that the increased fluid-flux signature in the Graben Segment could be the result of regional extension-driven decompression melting of lithospheric or asthenospheric mantle which was previously metasomatized by ancient subduction fluids and sediment melt. A similar process for the genesis of CAB-like signatures has been proposed elsewhere in the arc (Borg et al., 1997; Borg et al., 2002; Leeman et al., 2005), in the back-arc (Carlson et al., 2018), and in the Great Basin (Harry and Leeman, 1995). This provides a mechanism for increasing the fluid signature in the Graben Segment relative to the Washington Segment despite being a similar distance from major slab termini and similar subducted slab age and depth (Wilson, 2002; McCrory et al., 2012). This ancient metasomatism would also help explain the radiogenic $\mathrm{Pb}$ and $\mathrm{Sr}$ isotope signature of the primitive lavas in the region, although it should be noted that the Washington Segment has a slightly more radiogenic $\mathrm{Pb}$ isotopic signature, and isotopic data for the Graben Segment are scarce $(n=4)$.

\subsubsection{Depth of mantle melting and slab melting}

Differences in REE abundances between segments also suggest there are differences in the depth of melting and the degree to which slab melts contribute. The Garibaldi Segment of the arc has a bootstrapped mean composition that suggests greater involvement of garnet as a residual phase, thereby indicating deeper mantle melting than elsewhere in the arc. The segment has the lowest concentration of Y, Yb, Sc, Cr (Fig. 6), and has the steepest HREE depletion (Fig. 8). Furthermore, the bootstrapped mean occupies a unique position on a plot of $\mathrm{Dy} / \mathrm{Yb}$ vs. Dy/Dy* that is separate from the rest of the arc (Fig. 9). Mantle melting with amphibole (or clinopyroxene) residual would lead to a more concave MREE pattern (decrease in Dy/Dy*) with only a minor decrease in $\mathrm{Dy} / \mathrm{Yb}$. A garnet residuum leads to HREE depletion relative to MREE (large increase in Dy/Yb), with little change to the concavity of the REE (Dy/Dy*) (Davidson et al., 2013). While the rest of the arc lies within the variably enriched MORB-like field, the Garibaldi Segment lies at much higher $\mathrm{Dy} / \mathrm{Yb}$, indicating that it alone is characterized by deeper melting.

In addition, the Garibaldi Segment has the highest $\mathrm{Nb} / \mathrm{Zr}$ and $\mathrm{Nb} / \mathrm{Yb}$ (Fig. 10) of any segment, which may indicate a more enriched, IPB-like source (Pearce and Stern, 2006). In 
This article is a non-peer reviewed preprint published at EarthArXiv.

The article is in review by Geochimica et Cosmochimica Acta.

593 stark contrast, the neighboring segments to the south seem to lack the deep and enriched mantle melting signature. The Mount Baker and Glacier Peak regions have the highest $\mathrm{Y}, \mathrm{Yb}$, and Y/Zr

595 values and relatively low Dy/Dy*, Nb/Yb and Nb/Zr (Figs. 9 and 10) indicating a more depleted

596 source in which garnet is not likely a residual phase. Deep melting of an enriched mantle source

597 seen in the Garibaldi Segment may be the result of toroidal flow of enriched sub-slab mantle

598 around the northern edge of the Juan de Fuca plate, which becomes progressively diluted

599 southwards, as suggested by Mullen and Weis (2015). Our results indicate that the magnitude of

600 southward depletion is statistically significant over the one-degree latitude that separates Mount

601 Garibaldi and Mount Baker, thus leading to a segment boundary between them.

Slab melting could also contribute to the geochemical signature of the Garibaldi

603 Segment. In addition to having the highest $\mathrm{Dy} / \mathrm{Yb}$, the segment has the second highest $\mathrm{Sr} / \mathrm{Y}$ ratio

604 of any portion of the arc, a signature which has been used by many authors to suggest slab melting in arcs worldwide (Pearce and Peate, 1995; Stern and Kilian, 1996; Kelemen et al.,

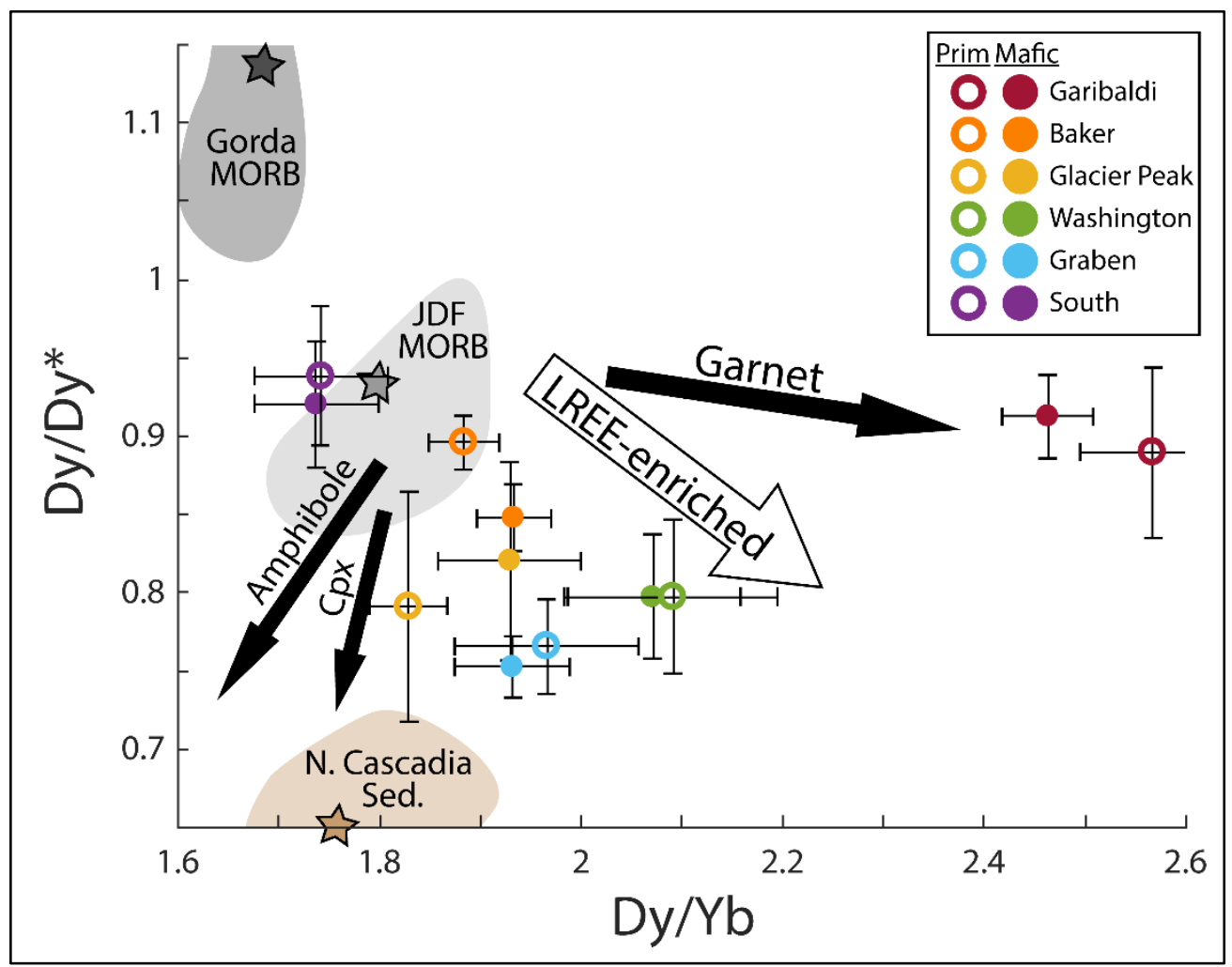

Figure 9: Dy/Yb vs. Dy/Dy* as defined by Davidson et al. (2012). Bootstrapped means of primitive and mafic compositions are shown. Fields of data from Gorda MORB (Davis et al., 2008), Juan de Fuca MORB (Gill et al., 2016), and offshore North Cascadia sediment (Carpentier et al., 2014) are also shown, along with the mean value (stars). Effect of enrichment of LREE is shown. Arrows indicate the effect of amphibole, clinopyroxene or garnet as residual phases during melting (Davidson et al., 2013). 
This article is a non-peer reviewed preprint published at EarthArXiv.

The article is in review by Geochimica et Cosmochimica Acta.

606 2003). Slab melting would be a reasonable process in this portion of the arc, since the slab is

607

608

609

610

611

612

613

614

615

616

617

618

619

620

621

622

623

624

625

626

627

628

629

630

631

632

633

634

635

636 much deeper (McCrory et al., 2012), and younger (3-5 Ma, Wilson, 2002). Additionally, toroidal flow of hot mantle has been suggested to cause thermal erosion of the edges of slabs (Thorkelson and Breitsprecher, 2005). However, we may expect slab melting to produce higher $\mathrm{SiO}_{2}$ as well as larger enrichments in $\mathrm{Zr}$ and $\mathrm{Hf}$ than we see in the Garibaldi Segment (Pearce and Peate, 1995).

Although Walowski et al. (2015) demonstrated that slab melting likely occurs in the southernmost Cascades beneath Lassen Peak, our bootstrapped data indicate that this may not be a dominant process throughout the entire South Segment, since the bootstrapped mean has high HREE, Y, Cr, and Sc, and the lowest Dy/Yb and Sr/Y of any segment. This is true even if we calculate bootstrapped mean of only the California portion of the Cascades. Thus, it is possible that slab melting in the South Segment is only localized to the region beneath Lassen Peak, where larger slab depths and hot toroidal flow may allow for more slab melting.

\subsubsection{Mantle fertility beneath the arc-front and rear-arc}

Although the enrichment of the Garibaldi Segment may be attributed to toroidal flow of sub-slab enriched mantle around the northern slab edge, a similar mechanism cannot explain the IPB-like enriched signature of both the Washington and Graben Segments which are not similarly situated near the terminal edge of a slab. These segments have the second or third highest concentrations of $\mathrm{Nb}, \mathrm{Zr}$, Ta (Fig. 6) and $\mathrm{Nb} / \mathrm{Yb}, \mathrm{Nb} / \mathrm{Zr}$ (Fig. 10), as well as the steepest REE patterns (Fig. 8) and thus highest $\mathrm{Ce} / \mathrm{Yb}$ (Fig. 7) of the arc-front. However, the Simcoe Volcanic Field, which lies in the rear-arc behind the Washington Segment, is more enriched than anywhere in the arc-front (Fig. 10). The enriched signature of the rear-arc compared to that of the Washington Segment, may indicate westward flow of enriched mantle (Leeman et al., 2005)which is first slightly depleted by the rear-arc volcanic field before being melted beneath the arc-front. A similar pattern of depletion from the back arc to the arc-front is seen in the IzuBonin, Scotia, and Marianas arcs (Pearce and Stern, 2006). Further evidence of the relationship between the enriched rear-arc mantle and the Washington Segment is provided by Mullen et al. (2017) who demonstrate that primitive lavas from Mt Adams deviate from the normal Cascades arc trend in terms of $\mathrm{Sr} \mathrm{Nd}$, and $\mathrm{Pb}$ isotopes and instead lie on a separate "Adams array" that trends toward a different Simcoe endmember. Slab-induced corner flow could provide the arc 
This article is a non-peer reviewed preprint published at EarthArXiv.

The article is in review by Geochimica et Cosmochimica Acta.

637 with enriched mantle material from the back arc (Long et al., 2012). Alternatively, a slab gap

638 such the one suggested by Gao and Shen (2014) to underlie the latitude of Mount Hood, could

639 provide both of the arc-front segments and the back-arc region with enriched sub-slab mantle

640 material. Either mechanism of upwelling deeper fertile mantle could also help to explain the

641 relatively deep melting signature (low HREE and Y/Zr) of the Graben and Washington Segments

642 (Figs 9, 10).

643 Our results also suggest that the IPB-like composition of the Washington and Graben

644 Segments is not likely due to interaction with the accreted Siletz terrain lithosphere as previous

645 authors have suggested (Church et al., 1986; Schmidt et al., 2008). Both segments lie within the

646 Columbia Embayment, a region of accreted oceanic crust (Trehu et al., 1994), that includes the

647 Late Paleocene-Eocene Siletz Terrain, interpreted to be an oceanic large igneous province (LIP)

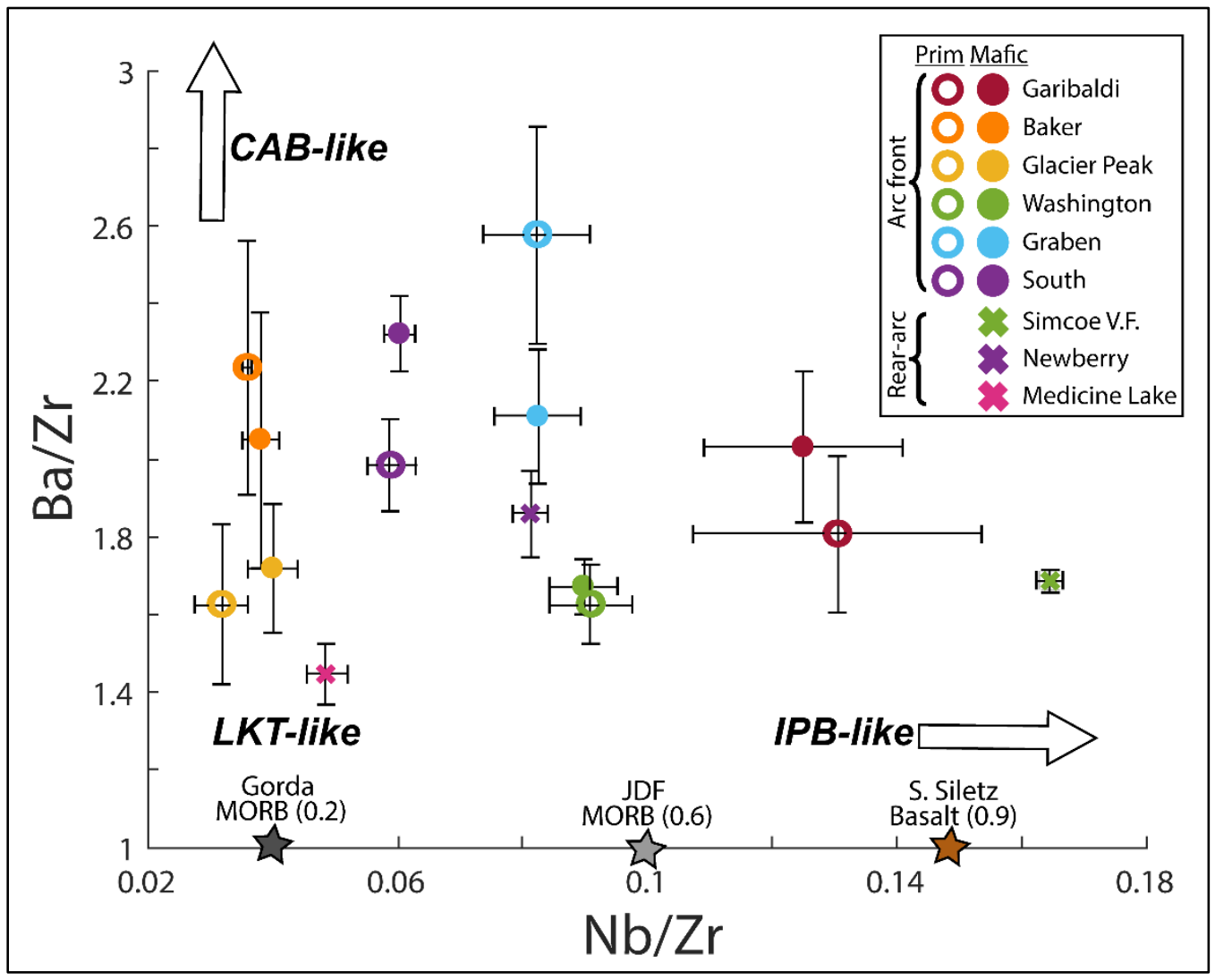

Figure 10: $\mathrm{Nb} / \mathrm{Zr}$ vs. Ba/Zr of bootstrapped means of new segments and rear-arc volcanoes. Mean $\mathrm{Nb} / \mathrm{Zr}$ values for Gorda MORB, JDF MORB, and Siletz basalt (south of $47^{\circ} \mathrm{N}$ ) are depicted, and $\mathrm{Ba} / \mathrm{Zr}$ values are in parentheses (Davis et al., 2008; Gill, et al., 2016; Phillips et al., 2017). Approximate locations of the three most common Cascades endmembers are shown.

with a plume-origin (Wells et al., 2014; Phillips et al., 2017). While some authors suggest based 
This article is a non-peer reviewed preprint published at EarthArXiv.

The article is in review by Geochimica et Cosmochimica Acta.

650 boundary (Finn, 1990; McCrory and Wilson, 2013; Bedrosian and Feucht, 2014), others hold that Siletzia lithosphere could extend well east of the arc, near the Idaho border (Gao et al., 2011). Assimilation of enriched Siletzia crust is unlikely since we would expect such assimilation to cause compositional differences between the primitive and mafic composition of a given segment, yet these bootstrapped means are indistinguishable for the Washington and Graben segments. Furthermore, although Siletz basalts (south of $47^{\circ} \mathrm{N}$ ) are slightly more enriched $\mathrm{Nb} / \mathrm{Yb}$ and $\mathrm{Nb} / \mathrm{Zr}$ (Phillips et al., 2017) than the primitive compositions of either Washington or Graben Segments, they are much less enriched than the Simcoe Volcanic Field (Fig. 10), indicating that Siletz mantle cannot be the source of the rear arc enrichment. Thus, we suggest that a westward flow of fertile mantle from the back arc is a more reasonable explanation for enrichment trends of these two segments and the rear arc Simcoe Volcanic Field.

A similar, albeit more reduced, depletion in $\mathrm{Nb} / \mathrm{Zr}$ is seen from the rear-arc Newberry volcano to the arc-front South Segment (Fig. 10), indicating that such mantle flow may be common in the middle portions of the arc. This mantle flow is further evidenced by trench perpendicular (east-west) mantle anisotropy observed by various studies (Long et al., 2009; Wannamaker et al., 2014; Long, 2016). It is possible that continuous depletion of westwardflowing mantle by the High Lava Plains volcanics of eastern Oregon (Long et al., 2012; Till et al., 2013)prior to being melted beneath Newberry has led it to have a more depleted signature than the Simcoe rear-arc volcanics to the north.

\section{Conclusions}

The Cascades arc exhibits significant along-strike variability in major and trace element compositions of mafic lavas, and numerous studies have proposed mechanisms such as mantle heterogeneity, regional tectonics and/or geochemical differences in the overlying lithosphere or subducting slab to be responsible for these compositional differences. Although considerable heterogeneity exists even at a single location, partitioning the arc into compositionally distinct groups allows one to explore the regional-scale causes for such differences. Schmidt et al. (2008)proposed a segmentation scheme for the Cascades that provides an excellent initial framework for such regional-scale studies. However, the study does not quantify differences between proposed segments, and is based on a limited dataset (390 samples) which is spatially biased toward only 11 arc-front locations. 
This article is a non-peer reviewed preprint published at EarthArXiv.

The article is in review by Geochimica et Cosmochimica Acta.

681

682

683

684

685

686

687

688

689

690

691

692

693

694

695

696

697

698

699

700

701

702

703

704

705

706

707

708

709

710

711

We improve on this study by compiling a dataset of major and trace element analyses of over 2,000 mafic samples and utilizing a Monte Carlo approach with bootstrap resampling to reduce the inherent bias that over-sampled volcanoes have on overall trends. In doing so, we can assess regional, rather than local processes. Our study develops a novel approach to assess geochemical variability by partitioning the arc using entirely objective and statistically-based methodology. Using this new approach, we separate the Cascades arc into 6 segments such that the geochemical differences between each is maximized. Although we demonstrate that those proposed by Schmidt et al. (2008) are statistically dissimilar from one another, we propose a new segmentation scheme, which includes the Garibaldi, Baker, Glacier Peak, Washington, Graben, and South Segments, which are up to 6.3 times more statistically distinct than the previous scheme. By separating the arc into the most statistically disparate regions, we can better assess the different processes that lead to geochemical heterogeneity within a single arc.

Our results demonstrate significant differences in mantle fertility, degree of melting, and input from the slab to each of the segment regions, which are briefly summarized below and in Table 4. The Garibaldi Segment is characterized by overall deeper melting of enriched mantle which may be the result of toroidal flow around the northern edge of the Juan de Fuca slab. The segment has the lowest fluid-flux signature, which may be due to the young (3-5 Ma) (Wilson, 2002) and thus hot slab, which may be largely dehydrated before the arc-front, and may cause the slab to undergo partial melting. In stark contrast, the neighboring Baker Segment to the south has a strong contribution from subduction fluids and is the result of melting a much more depleted mantle source. Because of these distinctions, the statistical difference between the Baker and Garibaldi Segments is penultimate in the arc. Thus, we suggest that Mount Baker should not be considered a part of the Garibaldi volcanic belt as numerous previous authors have advocated (Hildreth, 2007; Schmidt et al., 2008; Mullen and Weis, 2015; Mullen et al., 2017). Moving south, the Glacier Peak Segment is also characterized by significant fluid-flux melting of a depleted mantle source. However, it has the signature of much deeper fluids, consistent with its eastward position, where the slab is deeper $(>95 \mathrm{~km})$ than any other Cascades arc-front volcano (McCrory et al., 2012). In contrast, the Washington and Graben Segments are more enriched which may result from slab-induced corner flow or a slab gap. The relative enrichment of the rear-arc Simcoe Volcanic Field indicates that the mantle source of such enrichment is not associated with the accreted Siletz Terrain LIP. Although the fluid-flux signature of both 
This article is a non-peer reviewed preprint published at EarthArXiv.

The article is in review by Geochimica et Cosmochimica Acta.

712 segments is relatively low, the Graben Segment is more enriched in fluid mobile elements as

713 well as potential sediment melt indicators. We suggest that this difference between the two is a

714 result of extension in the Graben Segment which allows for more melting of mantle which had

715 been previously metasomatized by ancient fluids and sediment melts. Finally, the South Segment

716 has the largest CAB-like fluid-flux melting signature, which could partially result from increased

717 fluid penetration into the highly fractured Gorda plate. Alternatively, higher extension rates in

718 the South could cause melting of previously-metasomatized mantle at a higher degree than we

719 propose for the Graben Segment. Such a mechanism, which has also been suggested by previous

720 authors (Borg et al., 1997; Borg et al., 2002; Carlson et al., 2018), would explain the higher fluid

721 signature, higher degree melts, more radiogenic $\mathrm{Sr}, \mathrm{Pb}$, and $\mathrm{Nd}$ isotopic compositions observed

722 in the South Segment. Slab melting, as proposed for the Lassen Peak area (Walowski et al.,

723 2015), does not appear to be common signature observed elsewhere in the segment, and may be

724 localized to the southernmost volcanic edifice, where the slab is deeper and toroidal flow around

725 the slab edge could bring hot decompression melts that could erode the slab edge (Thorkelson

726 and Breitsprecher, 2005).

727 In this study, we have demonstrated the advantage of approaching important petrologic

728 questions, such as along-arc variability, using statistically rigorous methodology. With the

729 continual growth of online data repositories, scientists now have access to massive datasets that

730 can allow for much more detailed studies of particular regions or at the global scale. While these

731 data can be quite powerful, great care must be taken in assessing the quality of data and reducing

732 sampling bias. More complete and evenly-distributed sampling of arcs worldwide can allow

733 future studies to use our new methodology to investigate other compositionally heterogeneous

734 arcs in statistically robust manner.

735

736 Acknowledgements

737 We would like to thank Brenhin Keller for his advice during the initial stages of writing

738 the Bootstrap code. We would also like to thank the Oregon State University GEO 622 students

739 for their help in providing inspiration and advice during the initial stages of this project.

740 Funding for Bradley Pitcher was provided by the GeoPRISMS program of the National Science

741 Foundation [Award number 1144555]. 
This article is a non-peer reviewed preprint published at EarthArXiv.

The article is in review by Geochimica et Cosmochimica Acta.

\section{References}

Bacon C. R., Bruggman P. E., Christiansen R. L., Clynne M. A., Donnelly-Nolan J. M. and Hildreth W. (1997) PRIMITIVE MAGMAS AT FIVE CASCADE VOLCANIC FIELDS: MELTS FROM HOT, HETEROGENEOUS SUB.ARC MANTLE. 35.

Bedrosian P. A. and Feucht D. W. (2014) Structure and tectonics of the northwestern United States from EarthScope USArray magnetotelluric data. Earth Planet. Sci. Lett. 402, 275 289.

Blakely R. J., Christiansen R. L., Guffanti M., Wells R. E., Donnelly-Nolan J. M., Muffler L. J. P., Clynne M. A. and Smith J. G. (1997) Gravity anomalies, Quaternary vents, and Quaternary faults in the southern Cascade Range, Oregon and California: Implications for arc and backarc evolution. J. Geophys. Res. Solid Earth 102, 22513-22527.

Borg L. E., Blichert-Toft J. and Clynne M. A. (2002) Ancient and Modern Subduction Zone Contributions to the Mantle Sources of Lavas from the Lassen Region of California Inferred from Lu-Hf Isotopic Systematics. J. Petrol. 43, 705-723.

Borg L. E., Clynne M. A. and Btillen T. D. (1997) THE VARIABLE ROLE OF SLABDERIVED FLUIDS IN THE GENERATION OF A SUITE OF PRIMITIVE GALC.ALKALINE LAVAS FROM THE SOUTHERNMOST CASCADES, GALIFORNIA. Camdian Miner. gist 35, 42-452.

Brenan J. M., Shaw H. F., Ryerson F. J. and Phinney D. L. (1995) Mineral-aqueous fluid partitioning of trace elements at $900^{\circ} \mathrm{C}$ and $2.0 \mathrm{GPa}$ : Constraints on the trace element chemistry of mantle and deep crustal fluids. Geochim. Cosmochim. Acta 59, 3331-3350.

Brocher T. M., Wells R. E., Lamb A. P. and Weaver C. S. (2017) Evidence for distributed clockwise rotation of the crust in the northwestern United States from fault geometries and focal mechanisms. Tectonics, 2016TC004223.

Carlson R. W., Grove T. L. and Donnelly-Nolan J. M. (2018) Origin of Primitive Tholeiitic and Calc-Alkaline Basalts at Newberry Volcano, Oregon. Geochemistry, Geophys. Geosystems 19, 1360-1377.

Carpentier M., Weis D. and Chauvel C. (2014) Fractionation of Sr and Hf isotopes by mineral sorting in Cascadia Basin terrigenous sediments. Chem. Geol. 382, 67-82.

Carr M. J., Feigenson M. D., Patino L. C. and Walker J. A. (2004) Volcanism and Geochemistry in Central America: Progress and Problems. In Inside the Subduction Factory (ed. J. Eiler). 
This article is a non-peer reviewed preprint published at EarthArXiv.

The article is in review by Geochimica et Cosmochimica Acta.

773

774

775

776

777

778

779

780

781

782

783

784

785

786

787

788

789

790

791

792

793

794

795

796

797

798

799

800

801

802

803

American Geophysical Union. pp. 153-174.

Church S. E., Lehuray A. P., Grant A. R., Delevaux M. H. and Gray J. E. (1986) Lead-isotopic data from sulfide minerals from the Cascade Range, Oregon and Washington. Geochim. Cosmochim. Acta 50, 317-328.

Conrey R. (2004) SOTA Field Trip Guide. Oregon Dep. Geol. Miner. Ind. OFR-O-04-0.

Conrey R. M., Sherrod D. R., Hooper P. R. and Swanson D. A. (1997) Diverse primitive magmas in the Cascade Arc, northern Oregon and southern Washington. Can. Mineral. 35, 367-396.

Conrey R. M., Taylor E. M., Donnelly-Nolan J. M. and Sherrod D. R. (2002) North-central Oregon Cascades: Exploring petrologic and tectonic intimacy in a propagating intra-arc rift. F. Guid. to Geol. Process. Cascadia 36, 47-90.

Davidson J., Turner S. and Plank T. (2013) Dy/Dy*: Variations Arising from Mantle Sources and Petrogenetic Processes. J. Petrol. 54, 525-537.

Davis A. S., Clague D. A., Cousens B. L., Keaten R. and Paduan J. B. (2008) Geochemistry of basalt from the North Gorda segment of the Gorda Ridge: Evolution toward ultraslow spreading ridge lavas due to decreasing magma supply. Geochemistry, Geophys. Geosystems 9, n/a-n/a.

Donnelly-Nolan J. M., Grove T. L., Lanphere M. A., Champion D. E. and Ramsey D. W. (2008) Eruptive history and tectonic setting of Medicine Lake Volcano, a large rear-arc volcano in the southern Cascades. J. Volcanol. Geotherm. Res. 177, 313-328.

Elkins Tanton L. T., Grove T. L. and Donnelly-Nolan J. (2001) Hot, shallow mantle melting under the Cascades volcanic arc. Geology 29, 631.

Elliott T. (2003) Tracers of the slab. In American Geophysical Union (AGU). pp. 23-45.

Finn C. (1990) Geophysical constraints on Washington Convergent Margin Structure. J. Geophys. Res. 95, 19533.

Gao H., Humphreys E. D., Yao H. and van der Hilst R. D. (2011) Crust and lithosphere structure of the northwestern U.S. with ambient noise tomography: Terrane accretion and Cascade arc development. Earth Planet. Sci. Lett. 304, 202-211.

Gao H. and Shen Y. (2014) Upper mantle structure of the Cascades from full-wave ambient noise tomography: Evidence for 3D mantle upwelling in the back-arc. Earth Planet. Sci. Lett. 390, 222-233. 
This article is a non-peer reviewed preprint published at EarthArXiv.

The article is in review by Geochimica et Cosmochimica Acta.

804 Gill J., Michael P., Woodcock J., Dreyer B., Ramos F., Clague D., Kela J., Scott S., Konrad K.

805

806

807

808

809

810

811

812

813

814

815

816

817

818

819

820

821

822

823

824

825

826

827

828

829

830

831

832

833

834 and Stakes D. (2016) Spatial and Temporal Scale of Mantle Enrichment at the Endeavour Segment, Juan de Fuca Ridge. J. Petrol. 57, 863-896.

Green N. L. and Harry D. L. (1999) On the relationship between subducted slab age and arc basalt petrogenesis, Cascadia subduction system, North America. Earth Planet. Sci. Lett. 171, 367-381.

Grove T. L., Elkins-Tanton L. T., Parman S. W., Chatterjee N., Müntener O. and Gaetani G. A. (2003) Fractional crystallization and mantle-melting controls on calc-alkaline differentiation trends. Contrib. to Mineral. Petrol. 145, 515-533.

Grove T., Parman S., Bowring S., Price R. and Baker M. (2002) The role of an H2O-rich fluid component in the generation of primitive basaltic andesites and andesites from the Mt. Shasta region, N California. Contrib. to Mineral. Petrol. 142, 375-396.

Guffanti M. and Weaver C. S. (1988) Distribution of Late Cenozoic volcanic vents in the Cascade range: Volcanic arc segmentation and regional tectonic considerations. J. Geophys. Res. 93, 6513.

Harry D. L. and Leeman W. P. (1995) Partial melting of melt metasomatized subcontinental mantle and the magma source potential of the lower lithosphere. J. Geophys. Res. Solid Earth 100, 10255-10269.

HART W. K., ARONSON J. L. and MERTZMAN S. A. (1984) Areal distribution and age of low-K, high-alumina olivine tholeiite magmatism in the northwestern Great Basin. Geol. Soc. Am. Bull. 95, 186.

Hildreth W. (2007) Quaternary Magmatism in the Cascades: Geologic Perspectives - Wes Hildreth - Google Books. 1744th ed., US Geological Survey.

Hildreth W. and Moorbath S. (1988) Crustal contributions to arc magmatism in the Andes of Central Chile. Contrib. to Mineral. Petrol. 108, 247-252.

Ingebritsen S. E. and Mariner R. H. (2010) Hydrothermal heat discharge in the Cascade Range, northwestern United States. J. Volcanol. Geotherm. Res. 196, 208-218.

Kelemen P. B., Yogodzinski G. M. and Scholl D. W. (2003) Along-strike variation in the Aleutian Island Arc: Genesis of high Mg\# andesite and implications for continental crust. In American Geophysical Union (AGU). pp. 223-276.

Keller C. B. and Schoene B. (2012) Statistical geochemistry reveals disruption in secular 
This article is a non-peer reviewed preprint published at EarthArXiv.

The article is in review by Geochimica et Cosmochimica Acta.

lithospheric evolution about 2.5 Gyr ago. Nature 485, 490-493.

Keller C. B., Schoene B., Barboni M., Samperton K. M. and Husson J. M. (2015) Volcanicplutonic parity and the differentiation of the continental crust. Nature 523, 301-307.

Kessel R., Schmidt M. W., Ulmer P. and Pettke T. (2005) Trace element signature of subductionzone fluids, melts and supercritical liquids at 120-180 km depth. Nature 437, 724-727.

Labanieh S., Chauvel C., Germa A. and Quidelleur X. (2012) Martinique: a Clear Case for Sediment Melting and Slab Dehydration as a Function of Distance to the Trench. J. Petrol. 53, 2441-2464.

Leeman W. P., Lewis J. F., Evarts R. C., Conrey R. M. and Streck M. J. (2005) Petrologic constraints on the thermal structure of the Cascades arc. J. Volcanol. Geotherm. Res. 140, $67-105$.

Leeman W. P., Smith D. R., Hildreth W., Palacz Z. and Rogers N. (1990) Compositional diversity of Late Cenozoic basalts in a transect across the southern Washington Cascades: Implications for subduction zone magmatism. J. Geophys. Res. 95, 19561.

Little R. J. A. and Rubin D. B. (2014) Statistical Analysis with Missing Data., John Wiley \& Sons.

Long M. D. (2016) The Cascadia Paradox: Mantle flow and slab fragmentation in the Cascadia subduction system. J. Geodyn. 102, 151-170.

Long M. D., Gao H., Klaus A., Wagner L. S., Fouch M. J., James D. E. and Humphreys E. (2009) Shear wave splitting and the pattern of mantle flow beneath eastern Oregon. Earth Planet. Sci. Lett. 288, 359-369.

Long M. D., Till C. B., Druken K. A., Carlson R. W., Wagner L. S., Fouch M. J., James D. E., Grove T. L., Schmerr N. and Kincaid C. (2012) Mantle dynamics beneath the Pacific Northwest and the generation of voluminous back-arc volcanism. Geochemistry, Geophys. Geosystems 13, n/a-n/a.

Matsumoto M. and Nishimura T. (1998) Mersenne Twister: A 623-dimensionally Equidistributed Uniform Pseudo-random Number Generator. ACM Trans. Model. Comput. Simul. 8, 3-30.

McCaffrey R., Qamar A. I., King R. W., Wells R., Khazaradze G., Williams C. A., Stevens C. W., Vollick J. J. and Zwick P. C. (2007) Fault locking, block rotation and crustal deformation in the Pacific Northwest. Geophys. J. Int. 169, 1315-1340. 
This article is a non-peer reviewed preprint published at EarthArXiv.

The article is in review by Geochimica et Cosmochimica Acta.

866

867

868

869

870

871

872

873

874

875

876

877

878

879

880

881

882

883

884

885

886

887

888

889

890

891

892

893

894

895

896

McCrory P. A., Blair J. L., Waldhauser F. and Oppenheimer D. H. (2012) Juan de Fuca slab geometry and its relation to Wadati-Benioff zone seismicity. J. Geophys. Res. Solid Earth 117.

McCrory P. A. and Wilson D. S. (2013) A kinematic model for the formation of the SiletzCrescent forearc terrane by capture of coherent fragments of the Farallon and Resurrection plates. Tectonics 32, 718-736.

Meng X.-L. and Rubin D. B. (1993) Maximum likelihood estimation via the ECM algorithm: A general framework. Biometrika 80, 267-278.

Mojena R. (1977) Hierarchical grouping methods and stopping rules: an evaluation. Comput. J. 20, 359-363.

Mullen E. K. and Weis D. (2015) Evidence for trench-parallel mantle flow in the northern Cascade Arc from basalt geochemistry. Earth Planet. Sci. Lett. 414, 100-107.

Mullen E. K., Weis D., Marsh N. B. and Martindale M. (2017) Primitive arc magma diversity: New geochemical insights in the Cascade Arc. Chem. Geol. 448, 43-70.

Patino L. C., Carr M. J. and Feigenson M. D. (2000) Local and regional variations in Central American arc lavas controlled by variations in subducted sediment input. Contrib. to Mineral. Petrol. 138, 265-283.

Pearce J. A. (1982) Trace element characteristics of lavas from destructive plate boundaries. In Orogenic andesites and related rocks (ed. R. S. Thorpe). John Wiley and Sons, Chichester, England. pp. 528-548.

Pearce J. A. and Peate D. W. (1995) Tectonic Implications of the Composition of Volcanic ARC Magmas. Annu. Rev. Earth Planet. Sci. 23, 251-285.

Pearce J. A. and Stern R. J. (2006) Origin of back-arc basin magmas: Trace element and isotope perspectives. In American Geophysical Union (AGU). pp. 63-86.

Phillips B. A., Kerr A. C., Mullen E. K. and Weis D. (2017) Oceanic mafic magmatism in the Siletz terrane, NW North America: Fragments of an Eocene oceanic plateau? Lithos 274275, 291-303.

Pitcher B. W., Kent A. J. R., Grunder A. L. and Duncan R. A. (2017) Frequency and volumes of ignimbrite eruptions following the Late Neogene initiation of the Central Oregon High Cascades. J. Volcanol. Geotherm. Res. 339, 1-22.

Porritt R. W., Allen R. M., Boyarko D. C. and Brudzinski M. R. (2011) Investigation of Cascadia 
This article is a non-peer reviewed preprint published at EarthArXiv.

The article is in review by Geochimica et Cosmochimica Acta. segmentation with ambient noise tomography. Earth Planet. Sci. Lett. 309, 67-76.

Reiners P. W., Hammond P. E., McKenna J. M. and Duncan R. A. (2000) Young basalts of the central Washington Cascades, flux melting of the mantle, and trace element signatures of primary arc magmas. Contrib. to Mineral. Petrol. 138, 249-264.

Rowe M. C., Kent A. J. R. and Nielsen R. L. (2009) Subduction Influence on Oxygen Fugacity and Trace and Volatile Elements in Basalts Across the Cascade Volcanic Arc. J. Petrol. 50, $61-91$.

Ruscitto D. M., Wallace P. J., Johnson E. R., Kent A. J. R. and Bindeman I. N. (2010) Volatile contents of mafic magmas from cinder cones in the Central Oregon High Cascades: Implications for magma formation and mantle conditions in a hot arc. Earth Planet. Sci. Lett. 298, 153-161.

Schmidt M. E., Grunder A. L. and Rowe M. C. (2008) Segmentation of the Cascade Arc as indicated by $\mathrm{Sr}$ and $\mathrm{Nd}$ isotopic variation among diverse primitive basalts. Earth Planet. Sci. Lett. 266, 166-181.

Shaw A. M., Hilton D. R., Fischer T. P., Walker J. A. and Alvarado G. E. (2003) Contrasting $\mathrm{He}-\mathrm{C}$ relationships in Nicaragua and Costa Rica: insights into $\mathrm{C}$ cycling through subduction zones. Earth Planet. Sci. Lett. 214, 499-513.

Sherrod D. R. and Smith J. G. (1990) Quaternary extrusion rates of the Cascade Range, northwestern United States and southern British Columbia. J. Geophys. Res. Solid Earth 95, $19465-19474$.

Sisson T. W. and Layne G. D. (1993) H2O in basalt and basaltic andesite glass inclusions from four subduction-related volcanoes. Earth Planet. Sci. Lett. 117, 619-635.

Stern C. R. and Kilian R. (1996) Role of the subducted slab, mantle wedge and continental crust in the generation of adakites from the Andean Austral Volcanic Zone. Contrib. to Mineral. Petrol. 123, 263-281.

Syracuse E. M. and Abers G. A. (2006) Global compilation of variations in slab depth beneath arc volcanoes and implications. Geochemistry, Geophys. Geosystems 7, n/a-n/a.

Thorkelson D. J. and Breitsprecher K. (2005) Partial melting of slab window margins: genesis of adakitic and non-adakitic magmas. Lithos 79, 25-41.

Till C. B., Grove T. L., Carlson R. W., Donnelly-Nolan J. M., Fouch M. J., Wagner L. S. and Hart W. K. (2013) Depths and temperatures of \&1t;10.5 Ma mantle melting and the 
This article is a non-peer reviewed preprint published at EarthArXiv.

The article is in review by Geochimica et Cosmochimica Acta.

928

929

930

931

932

933

934

935

936

937

938

939

940

941

942

943

944

945

946

947

948

949

950

951

952

953

954

955

956

957

958

lithosphere-asthenosphere boundary below southern Oregon and northern California. Geochemistry, Geophys. Geosystems 14, 864-879.

Trehu A. M., Asudeh I., Brocher T. M., Luetgert J. H., Mooney W. D., Nabelek J. L. and Nakamura Y. (1994) Crustal Architecture of the Cascadia Forearc. Science (80-. ). 266, $237-243$.

Tryon C. A., Kuhn S. L., Slimak L., Logan M. A. V. and Balkan-Atlı N. (2011) Scale in tephrostratigraphic correlation: An example from Turkish Pleistocene archaeological sites. Quat. Int. 246, 124-133.

Turner S. and Foden J. (2001) U, Th and Ra disequilibria, Sr, Nd and Pb isotope and trace element variations in Sunda arc lavas: predominance of a subducted sediment component. Contrib. to Mineral. Petrol. 142, 43-57.

Verplanck E. P. and Duncan R. A. (1987) Temporal variations in plate convergence and eruption rates in the Western Cascades, Oregon. Tectonics 6, 197-209.

Walowski K. J., Wallace P. J., Hauri E. H., Wada I. and Clynne M. A. (2015) Slab melting beneath the Cascade Arc driven by dehydration of altered oceanic peridotite. Nat. Geosci. 8, 404-408.

Wannamaker P. E., Evans R. L., Bedrosian P. A., Unsworth M. J., Maris V. and McGary R. S. (2014) Segmentation of plate coupling, fate of subduction fluids, and modes of arc magmatism in Cascadia, inferred from magnetotelluric resistivity. Geochemistry, Geophys. Geosystems 15, 4230-4253.

Wells R., Bukry D., Friedman R., Pyle D., Duncan R., Haeussler P. and Wooden J. (2014) Geologic history of Siletzia, a large igneous province in the Oregon and Washington Coast Range: Correlation to the geomagnetic polarity time scale and implications for a long-lived Yellowstone hotspot. Geosphere 10, 692-719.

Wells R. E. and McCaffrey R. (2013) Steady rotation of the Cascade arc. Geology 41, 10271030.

Wells R. E., Weaver C. S. and Blakely R. J. (1998) Fore-arc migration in Cascadia and its neotectonic significance. Geology 26, 759.

Whitford D. J., Nicholls I. A. and Taylor S. R. (1979) Spatial variations in the geochemistry of quaternary lavas across the Sunda arc in Java and Bali. Contrib. to Mineral. Petrol. 70, 341-356. 
959 Wilson D. S. (2002) The Juan de Fuca plate and slab: Isochron structure and Cenozoic plate motions. In THE CASCADIA SUBDUCTION ZONE AND RELATED SUBDUCTION SYSTEMS Seismic Structure, Intraslab Earthquakes and Processes, and Earthquake Hazards. OFR 02-328 (eds. S. Kirby, K. Wang, and S. Dunlop). US Geological Survey. pp. 9-12.

965 Rift System. Eos, Trans. Am. Geophys. Union 86, 255.

966 Wörner G., Moorbath S., Horn S., Entenmann J., Harmon R. S., Davidson J. P. and Lopez967 Escobar L. (1994) Large- and Fine-Scale Geochemical Variations Along the Andean Arc of 968 Northern Chile $\left(17.5^{\circ}-22^{\circ} \mathrm{S}\right)$. In Tectonics of the Southern Central Andes (eds. P. D. K.-J.

969 Reutter, D. E. Scheuber, and D. P. J. Wigger). Springer Berlin Heidelberg. pp. 77-92. 